Research Paper

\title{
The Prognostic Value of aspartate aminotransferase to lymphocyte ratio and systemic immune-inflammation index for Overall Survival of Hepatocellular Carcinoma Patients Treated with palliative Treatments
}

Li-Yun Zhao ${ }^{1^{*}}$, Dong-Dong Yang2 ${ }^{2}$, Xiao-Kun Ma1 ${ }^{*}$, Meng-Meng Liu ${ }^{1^{*}}$, Dong-Hao $\mathrm{Wu}^{1}$, Xiao-Ping Zhang ${ }^{3}$ Dan-Yun Ruan ${ }^{1}$, Jin-Xiang Lin ${ }^{1}$, Jing-Yun Wen ${ }^{1}$, Jie Chen ${ }^{1}$, Qu Lin¹, Min Dong ${ }^{1}$, Jing-Jing Qi², Pei-Shan Hu², Zhao-Lei Zeng ${ }^{2}$, Zhan-Hong Chen ${ }^{1,2}$, Xiang-Yuan Wu ${ }^{1 凶}$

1. Department of Medical Oncology and Guangdong Key Laboratory of Liver Disease, Third Affiliated Hospital of Sun Yat-sen University, 600 Tianhe Road, Guangzhou, 510630, China

2. Department of Medical Oncology of Sun Yat-sen University Cancer Center, State Key Laboratory of Oncology in South China, Collaborative Innovation Center for Cancer Medicine, 651 Dongfengdong Road, Guangzhou, 510060, China

3. Meihua Street Community Health Service Center, Yuexiu District Guangzhou, 510000, China

* These authors contributed equally to this work

$\triangle$ Corresponding authors: Zhan-Hong Chen: Address: Department of Medical Oncology and Guangdong Key Laboratory of Liver Disease, Third Affiliated Hospital of Sun Yat-sen University, 600 Tianhe Road, Guangzhou 510630, People's Republic of China; Tel.: +86-20-85252212; E-mail: chzhanh3@mail.sysu.edu.cn or Xiang-Yuan Wu: Address: Department of Medical Oncology and Guangdong Key Laboratory of Liver Disease, Third Affiliated Hospital of Sun Yat-sen University, 600 Tianhe Road, Guangzhou 510630, People's Republic of China; Tel.: +86-20-85252212; E-mail: wuxiangy@mail.sysu.edu.cn

(C) Ivyspring International Publisher. This is an open access article distributed under the terms of the Creative Commons Attribution (CC BY-NC) license (https://creativecommons.org/licenses/by-nc/4.0/). See http://ivyspring.com/terms for full terms and conditions.

Received: 2018.10.14; Accepted: 2019.03.07; Published: 2019.05.21 
III $(\mathrm{HR}=3.921, P=0.010)$. The SIl was identified as an independent prognostic factor in training cohort $(H R=1.356, P=0.020)$ and the validation cohort II $(H R=2.678, P=0.002)$. The prognostic nomogram including ALRI was the best in predicting 3-month, 6-month, 1-year, 2-year survival And OS among TNM, ALRI, ALRI-TNM and nomogram.

Conclusions: The ALRI was a novel independent prognostic index for the HCC patients treated with palliative treatments.

Key words: ALRI; palliative treatment; hepatocellular carcinoma; prognostic factors; nomogram

\section{Introduction}

Liver cancer is a highly malignant tumour with high incidence rate and mortality rate globally [1]. The incidence of liver cancer ranks the fifth while the mortality rate ranks the second worldwide [2, 3]. Liver cancer is also a heavy disease burden for China because China accounts for half of all liver cancer patients worldwide [4].One of the most common pathological types of liver cancer is hepatocellular carcinoma (HCC) [5]. In China, only $25 \%$ of HCC patients can be treated with radical surgery while $75 \%$ of HCC patients are diagnosed at advanced or locally advanced stage, for whom palliative treatments including sorafenib, lenvatinib, immune checkpoint inhibitor, chemotherapy, transhepatic arterial chemotherapy and embolization (TACE) or best supportive care are needed to prolong overall survival (OS) and relieve suffering of patients [6].

The prognosis of HCC patients receiving palliative treatments is very heterogeneous, with OS ranging from several months to several years [7]. It is truly important to look for the factors independently influencing the prognosis of HCC patients and to make risk stratification for patients with HCC to adopt corresponding treatments $[8,9]$. The prognosis of HCC is related to tumour status, liver function, patients' immunity and inflammatory state, etc. For HCC patients, several staging systems were proposed to predict prognosis. The most recognized systems include the Cancer of the Liver Italian Program (CLIP) score, the Barcelona clinic liver cancer (BCLC) staging system and the Tumour-Node-Metastasis (TNM) staging system, etc [10-12]. The relationship between serological factors and the prognosis of HCC has caught much attention of researchers due to easy access and convenience of serological factors in clinical practice. Our team have explored the prognostic values of lymphocyte and monocyte ratio (LMR), neutrophil-to-lymphocyte ratio (NLR), platelet-to-lymphocyte ratio (PLR) in HCC patients with TACE treatments, chemotherapy or surgery. Given that most of HCC patients are associated with liver cirrhosis and chronic hepatitis B infection in China, it is not surprising that these inflammatory markers are associated with the prognosis of HCC [13, 14].
Apart from inflammation-related prognostic factors, serological indicators reflecting liver function or immune status may also be prognostic factors of HCC patients [15]. Many researchers have found that lymphocytes are very important in host anticancer immune responses and affect tumour prognosis [16]. Aspartate aminotransferase (AST) to lymphocyte ratio (ALRI) [17], systemic immune-inflammation index (SII) [18] and aspartate aminotransferase to platelet count ratio index (APRI) [19] are serological indices reflecting liver function or immune status. However, little attention was paid to the ALRI, APRI and SII in HCC patients treated with palliative treatments.

In this research, we explored the prognostic values of ALRI, APRI, SII in a large cohort of 598 HCC participants with palliative treatments. All the patients were randomly assigned to training cohort (429 patients) and validation cohort I (169 patients). The prognostic values of ALRI, APRI, SII were explored both in the training cohort and the validation cohort I. We also established a nomogram including ALRI to explore whether the integration of ALRI into nomogram would have a better prognostic value. We validated the prognostic value of the ALRI, SII and APRI with two independent cohorts, the validation cohort II and the validation cohort III. The validation cohort II was consisted of 82 HCC patients treated with TACE and the validation cohort III was consisted of 150 HCC patients treated with curative resection.

\section{Methods}

\section{Patients}

After approve of the institutional review board and after written informed consent were obtained from patients or their family members. Clinical data of 598 HCC patients with palliative treatments at the Third Affiliated Hospital of Sun Yat-sen University between July 2009 and December 2013 was retrospectively reviewed and collected. The patients were randomly assigned into two groups: the training cohort of 429 patients and the validation cohort I of 169 patients. 
Clinical data of 82 HCC patients treated with TACE and 150 HCC patients treated with curative resection at the Third Affiliated Hospital of Sun Yat-sen University between January 2014 and December 2014 was retrospectively reviewed and collected.

All participants fulfilled the criteria below: (1) The diagnosis of HCC was either verified by pathology results or confirmed according to radiological criteria from the American Association for the Study of Liver Diseases; (2) Patients received palliative treatments; (3) No history or concurrence of other malignant cancers; (4) Clinicopathological data and follow-up data were complete.

\section{Data collection}

From electronic medical record system of our hospital, we collected the entire cohort's demographic and clinical data which includes gender, age of diagnosis, liver function data, blood routine tests and oncological examination, tumour stage, cancer biomarkers, tumour histology and radiological results. All the patients were regularly followed up. The OS was defined as the date of the initial diagnosis to the date of death or the date of the last follow-up.

The ALRI index is defined as the ratio of aspartate aminotransferase to lymphocytes and is calculated using the following formula: AST value $(\mathrm{U} / \mathrm{L}) /$ lymphocyte count $\left(\times 10^{9} / \mathrm{L}\right)$. SII is defined as Platelet count $\times$ Neutrophil count /Lymphocyte count $\left(\times 10^{9} / \mathrm{L}\right)$. APRI is calculated as $[100 /$ Platelet count $\left.\left(\times 10^{9} / \mathrm{L}\right)\right] \times[$ AST value $(\mathrm{U} / \mathrm{L}) /$ upper limit normal].

\section{Statistical analysis}

There were four cohorts in our study: the training cohort, the validation cohort I, the validation cohort II and the validation cohort III. ROC curves were used in the training cohort to obtain the best cut-off values for the ALRI, SII and APRI. The best cut-off values were further validated in the validation cohort I. In both cohorts, all the patients were further subdivided into high ALRI group and low ALRI group. Comparisons between the means of the continuous variables were analysed by the Student's $t$ test while the comparisons between the medians were carried out by the Mann-Whitney tests. Chi-square test and Fisher's exact test were made use of to explore the correlation of ALRI levels with other clinical variables. The ALRI levels of HCC patients with different clinical pathological conditions were also compared and the results were shown as the scatter plots. We identified independent prognostic factors in both cohorts with univariate analysis by Kaplan-Meier method (log-rank test) and multivariate analysis by Cox proportional hazards regression models. A two-tail $P<0.05$ was statistically significant. A prognostic nomogram incorporating ALRI, PVTT, distant metastasis, BUN and Child-Pugh grade were performed by the rms package in $\mathrm{R}$ project based on the training cohort and validated in the validation cohort I. The prognostic value of ALRI was further validated in the validation cohort II and the validation cohort III. The performance of the nomogram was evaluated by concordance index(C-index). Akaike information criterion (AIC) and likelihood ratio test (LRT) were applied to compare prognostic abilities of different systems in predicting OS. All analysis was calculated within the use of SPSS (version 24.0; IBM Corp., Armonk, NY, USA), GraphPad Prism 6.0 (GraphPad Software Inc., LaJolla, CA, USA), R project version 3.3.3 (http://www.r-project.org/)and Medcalc (version 15.8; MedCalc Software bvba, Acacialaan, Belgium).

\section{Results}

\section{Demographic and clinical characteristics}

We enrolled 830 HCC patients in the study and we randomly assigned them into the training cohort (429 patients), the validation cohort I (169 patients), the validation cohort II (82 patients) and the validation cohort III (150 patients). Baseline demographic data are shown in table 1 and table 7.

In the training cohort, the median age was 54(IQR 45-63) years. The proportion of male HCC is much higher than that of female in the training cohort, $392(91.4 \%)$ of the patients were male. The proportion of HCC patients without ascites far exceeds that of those with ascites, 143(33.3\%) were diagnosed with ascites. As for the liver and kidney function values, median levels of HGB, GGT, BUN, ALB, TB, ALT, AST, ALP and PLT were $128 \mathrm{~g} / \mathrm{L}, 130.5 \mathrm{U} / \mathrm{L}, 5.02$ $\mathrm{mmol} / \mathrm{L}, 37 \mathrm{~g} / \mathrm{L}, 20.3 \mathrm{mmol} / \mathrm{L}, 46 \mathrm{U} / \mathrm{L}$,68 U/L ,113 $\mathrm{U} / \mathrm{L}$ and $133 \times 10^{9} / \mathrm{L}$ respectively. More than half of HCC patients $(51.3 \%)$ were with portal vein tumor thrombosis (PVTT) in the training cohort. In the validation cohort I, the median age was 52 (IQR 43-61) years. The number of male patients was 151 (89.3\%) and $61(36.1 \%)$ patients were with ascites. For laboratory test values in the validation cohort $\mathrm{I}$, the median levels of HGB, GGT, BUN, ALB, TB, ALT, AST, ALP and PLT were $129 \mathrm{~g} / \mathrm{L}, 154 \mathrm{U} / \mathrm{L}, 5.13$ mmol / L, $35.8 \mathrm{~g} / \mathrm{L}, 14.8 \mathrm{mmol} / \mathrm{L}, 49 \mathrm{U} / \mathrm{L}, 83 \mathrm{U} / \mathrm{L}$, $136 \mathrm{U} / \mathrm{L}$ and $206 \mathrm{U} / \mathrm{L}$ respectively. In the validation cohort I, 96 (56.8\%) patients were with PVTT. We statistically compared the training and validation cohort. The results were displayed in table 1 .

In the validation cohort II, the median age was 56 (IQR 44-63) years. The proportion of male patients was $75(91.5 \%)$ and $12(14.6 \%)$ patients were with 
ascites. The median levels of HGB, GGT, ALB, TB, ALT, AST, ALP and PLT were $136.50 \mathrm{~g} / \mathrm{L}, 96 \mathrm{U} / \mathrm{L}$, $38.05 \mathrm{~g} / \mathrm{L}, 16.55 \mathrm{mmol} / \mathrm{L}, 41.50 \mathrm{U} / \mathrm{L}, 47 \mathrm{U} / \mathrm{L}, 105 \mathrm{U}$ / $\mathrm{L}$ and $147.5 \times 10^{9} / \mathrm{L}$ respectively and $15(18.3 \%)$ patients were with PVTT. In the validation cohort III, the median age was 48 (IQR $38-57$ ) years. The number of male patients accounts for $131(87.3 \%)$ and $24(16.0 \%)$ patients were with ascites. The median levels of HGB, GGT, ALB, TB, ALT, AST, ALP and PLT were $142 \mathrm{~g} / \mathrm{L}, 49.5 \mathrm{U} / \mathrm{L}, 41.85 \mathrm{~g} / \mathrm{L}, 16.28 \mathrm{mmol}$ / L, 35.50U / L, 38.50U / L, 73U / L and $164 \times 10^{9} / \mathrm{L}$ respectively and 22(14.7\%) patients were with PVTT.

Table 1. Baseline demographics and clinical characteristics of the training cohort and the validation cohort $\mathrm{I}$.

\begin{tabular}{|c|c|c|c|c|}
\hline \multicolumn{2}{|l|}{ Characteristics } & $\begin{array}{l}\text { Training Cohort, } \mathbf{n} \\
(\%)\end{array}$ & $\begin{array}{l}\text { Validation Cohort I, } \\
\mathrm{n}(\%)\end{array}$ & $\begin{array}{l}P \\
\text { value }\end{array}$ \\
\hline \multicolumn{2}{|l|}{ Total } & $429(100)$ & 169(100) & \\
\hline \multicolumn{2}{|c|}{ Age, years (median/IQR) } & $54(45-63)$ & $52(43-61)$ & 0.069 \\
\hline \multirow[t]{2}{*}{ Gender } & Male & 392(91.4) & 151(89.3) & 0.435 \\
\hline & Female & $37(8.6)$ & $18(10.7)$ & \\
\hline \multirow[t]{2}{*}{ Ascites } & Yes & $143(33.3)$ & $61(36.1)$ & 0.566 \\
\hline & No & $286(66.7)$ & $108(63.9)$ & \\
\hline \multicolumn{5}{|c|}{ Laboratory parameters (median/IQR) } \\
\hline \multicolumn{2}{|l|}{ HGB, g/L } & $128.00(114.00-142.00)$ & $129.00(113.00-143.00)$ & 0.897 \\
\hline \multicolumn{2}{|l|}{ GGT, U/L } & $130.50(71.25-252.50)$ & $154.00(81.00-335.00)$ & 0.024 \\
\hline \multicolumn{2}{|l|}{ BUN, mmol/L } & $5.02(4.02-6.15)$ & $5.13(3.90-6.93)$ & 0.025 \\
\hline \multicolumn{2}{|l|}{$\mathrm{ALB}, \mathrm{g} / \mathrm{L}$} & $37.00(33.15-41.00)$ & $35.80(32.55-40.25)$ & 0.036 \\
\hline \multicolumn{2}{|l|}{$\mathrm{TB}, \mathrm{mmol} / \mathrm{L}$} & $20.30(13.40-35.85)$ & $14.81(10.80-23.26)$ & 1.000 \\
\hline \multicolumn{2}{|l|}{ ALT, U/L } & $46.00(34.00-69.00)$ & $49.00(32.00-81.00)$ & 0.687 \\
\hline \multicolumn{2}{|l|}{ AST, U/L } & $68.00(43.00-126.00)$ & $83.00(44.00-167.20)$ & 0.702 \\
\hline \multicolumn{2}{|l|}{ ALP, U/L } & $113.00(87.00-169.50)$ & $136.00(97.15-216.55)$ & $<0.001$ \\
\hline \multicolumn{2}{|l|}{ PLT, $\times 10^{9} / \mathrm{L}$} & $133.00(83.00-191.00)$ & $206.00(147.50-260.00)$ & 0.002 \\
\hline \multirow[t]{2}{*}{$\mathrm{AFP}, \mathrm{ng} / \mathrm{mL}$} & $>400$ & $200(46.6)$ & $95(56.2)$ & 0.037 \\
\hline & $\leq 400$ & $229(53.4)$ & $74(43.8)$ & \\
\hline \multirow[t]{2}{*}{ PVTT } & Yes & $220(51.3)$ & $96(56.8)$ & 0.238 \\
\hline & No & 209(48.7) & $73(43.2)$ & \\
\hline \multirow[t]{3}{*}{ Child-Pugh grade } & A & $253(59.0)$ & $89(52.7)$ & 0.104 \\
\hline & B & $141(32.9)$ & $57(33.7)$ & \\
\hline & $\mathrm{C}$ & $35(8.1)$ & $23(13.6)$ & \\
\hline \multirow[t]{2}{*}{ SII } & $>376.4$ & $189(44.1)$ & $145(85.8)$ & $<0.001$ \\
\hline & $\leq 376.4$ & $240(55.9)$ & $24(14.2)$ & \\
\hline \multirow[t]{2}{*}{ APRI } & $>1.37$ & $242(56.4)$ & $79(46.7)$ & 0.036 \\
\hline & $\leq 1.37$ & 187(43.6) & $90(53.3)$ & \\
\hline \multirow[t]{2}{*}{ ALRI } & $>86.3$ & $260(60.6)$ & $81(47.9)$ & 0.006 \\
\hline & $\leq 86.3$ & $169(39.4)$ & $88(52.1)$ & \\
\hline \multirow{2}{*}{$\begin{array}{l}\text { T category (AJCC } \\
7 \text { th) }\end{array}$} & T1-2 & $115(26.8)$ & $29(17.2)$ & $<0.001$ \\
\hline & T3-4 & $314(73.2)$ & $140(82.8)$ & \\
\hline \multirow{2}{*}{$\begin{array}{l}\mathrm{N} \text { category (AJCC } \\
\text { 7th) }\end{array}$} & No & $345(80.4)$ & $120(71.0)$ & 0.016 \\
\hline & N1 & 84(19.6) & $49(29.0)$ & \\
\hline \multirow{2}{*}{$\begin{array}{l}\text { M category (AJCC } \\
7 \text { th) }\end{array}$} & M0 & $383(89.3)$ & $137(81.1)$ & 0.010 \\
\hline & M1 & $46(10.7)$ & $32(18.9)$ & \\
\hline \multirow{4}{*}{$\begin{array}{l}\text { NCCN-TNM stage } \\
\text { (AJCC 7th) }\end{array}$} & I & $34(7.9)$ & $15(8.9)$ & 0.002 \\
\hline & II & $73(17.0)$ & $11(6.5)$ & \\
\hline & III & $210(49.0)$ & $82(48.5)$ & \\
\hline & IV & $112(26.1)$ & $61(36.1)$ & \\
\hline
\end{tabular}

HGB: haemoglobin; GGT: glutamyl transpeptidase; BUN: blood urea nitrogen; ALB: albumin; TB: total bilirubin; ALT: alanine transaminase; AST: Aspartate Transaminase; ALP: alkaline phosphatase; PLT: platelet; AFP: alpha fetoprotein; PVTT: portal vein tumor thrombosis; SII: systemic immune-inflammation index APRI: aspartate aminotransferase to platelet count ratio index; ALRI: aspartate aminotransferase to lymphocyte ratio; NCCN: The National Comprehensive Cancer Network; AJCC: The American Joint Committee on Cancer; TNM: tumour-node-metastasis.
The best cut-off values defined by ROC analysis for ALRI, SII and APRI were 86.3, 376.4 and 1.3 respectively in the training cohort. HCC patients with high APRI, high SII and high ALRI accounted for $56.4 \%, 44.1 \%$ and $60.6 \%$ in the training cohort while $46.7 \%, 85.8 \%$ and $47.9 \%$ in the validation cohort I. There are $73.2 \%$ of the patients classified as T3-4, $19.6 \%$ with lymph node metastasis and $10.7 \%$ with distant metastasis in the training cohort while $82.8 \%$, $29.0 \%$ and $18.9 \%$ in the validation cohort I.

\section{Correlation analysis of ALRI index in different HCC subgroups in the training cohort and the validation cohort I}

Patients were stratified into high ALRI group (ALRI>86.3) and low ALRI group (ALRI $\leq 86.3$ ). We analyzed the association between ALRI and other clinicopathological variables. As displayed in table 2 $\& 3$, the patients in the high ALRI group had obviously higher levels of TB, AST and ALP in the training cohort $(48.8 \%$ vs. $30.2 \%, P<0.001 ; 94.2 \%$. vs. $72.2 \%, P<0.001 ; 23.1 \%$. vs. $5.3 \%, P<0.001$, respectively) while the patients in the high ALRI group had obviously higher levels of TB, AST, ALP and AFP in the validation cohort I $(59.3 \%$ vs. $25.0 \%$, $P<0.001$; 91.4\%. vs.77.3\%, $P=0.02 ; 45.7 \%$. vs. $14.8 \%$, $P<0.001 ; 67.9 \%$. vs. $45.5 \%, P=0.005$, respectively). ALRI>86.3 was significantly associated with higher frequencies of Child-Pugh $B \& C$, portal vein tumor thrombosis (PVTT) and ascites both in the training cohort and the validation cohort I $(P<0.05)$.

\section{Comparisons of ALRI level of HCC patients}

As we can see in the Figure 1, the ALRI level of HCC patients with Child-Pugh B \& C was significantly higher than that of HCC patients with Child-Pugh A $(202.7 \pm 12.53$ vs. $147.7 \pm 10.76 \mathrm{~N}=342$, $P=0.0009$ ). The same trend can be seen for those with ascites compared to those without ascites (218.6 \pm 14.85 vs. $146.8 \pm 9.630, P<0.0001)$, as well as those with PVTT compared to those without PVTT (219.5 \pm 13.82 vs. $117.3 \pm 6.753, P<0.0001)$.

\section{Univariate and multivariate analysis of prognostic variables in HCC patients}

In the training cohort, as we can see in the Figure 2 , univariate analysis showed that the OS of HCC patients with high ALRI, ALB $\leq 36 \mathrm{~g} / \mathrm{L}, \mathrm{TB}>$ $23.9 \mathrm{mmol} / \mathrm{L}, \mathrm{AFP}>400 \mathrm{ng} / \mathrm{ml}, \mathrm{BUN}>8.9 \mathrm{mmol} / \mathrm{L}$, TNM III-IV, T3-4, PVTT, distant metastasis and ascites was significantly shorter $(P<0.05)$. We applied a Cox's proportional hazards regression model to further analyse all the factors significantly prognostic of OS in the univariate analysis, with the attempt to find out the independent prognostic factors of OS in the 
training cohort. The results showed that ALRI $>86.3$ (HR=1.481; 95\% CI, 1.138 to $1.927 ; P=0.004)$ and SII $(\mathrm{HR}=1.356 ; 95 \% \mathrm{CI}, 1.052$ to $1.749 ; P=0.020)$ were independent prognostic factors for OS in the training cohort.

Table 2. The Chi-square analysis of the clinicopathologic variables between the high-ALRI and low-ALRI groups in the training cohort.

\begin{tabular}{|c|c|c|c|c|}
\hline \multicolumn{2}{|l|}{ Variables } & \multirow{2}{*}{$\begin{array}{l}\text { Group A } \\
\text { ALRI }>86.3\end{array}$} & \multirow{2}{*}{$\begin{array}{l}\text { Group B } \\
\text { ALRI } \leq 86.3\end{array}$} & \multirow[t]{2}{*}{$P$ value } \\
\hline & & & & \\
\hline & & $(n=260)$ & $(n=169)$ & \\
\hline \multirow[t]{2}{*}{ Age, years } & $>54$ & $139(53.5 \%)$ & $83(49.1 \%)$ & 0.429 \\
\hline & $\leq 54$ & $121(46.5 \%)$ & $86(50.9 \%)$ & \\
\hline \multirow[t]{2}{*}{ Gender } & Male & $27(10.4 \%)$ & $10(5.9 \%)$ & 0.116 \\
\hline & Female & $233(89.6 \%)$ & $159(94.1 \%)$ & \\
\hline \multirow[t]{2}{*}{ Ascites } & Yes & $115(44.2 \%)$ & $28(16.6 \%)$ & $<0.001$ \\
\hline & No & $145(55.8 \%)$ & $141(83.4 \%)$ & \\
\hline \multicolumn{5}{|c|}{ Laboratory parameters (median/IQR) } \\
\hline \multirow[t]{2}{*}{$\mathrm{HGB}, \mathrm{g} / \mathrm{L}$} & $>150$ & $30(11.5 \%)$ & $31(18.3 \%)$ & 0.065 \\
\hline & $\leq 150$ & $230(88.5 \%)$ & $138(81.7 \%)$ & \\
\hline \multirow[t]{2}{*}{ BUN, mmol/L } & $>8.9$ & $16(6.2 \%)$ & $5(3.0 \%)$ & 0.171 \\
\hline & $\leq 8.9$ & $244(93.8 \%)$ & $164(97.0 \%)$ & \\
\hline \multirow[t]{2}{*}{$A L B, g / L$} & $>36$ & $137(52.7 \%)$ & $108(63.9 \%)$ & 0.028 \\
\hline & $\leq 36$ & $123(47.3 \%)$ & $61(36.1 \%)$ & \\
\hline \multirow[t]{2}{*}{$\mathrm{TB}, \mathrm{mmol} / \mathrm{L}$} & $>23.9$ & $127(48.8 \%)$ & $51(30.2 \%)$ & $<0.001$ \\
\hline & $\leq 23.9$ & $133(51.2 \%)$ & $118(69.8 \%)$ & \\
\hline \multirow[t]{2}{*}{ AST, U/L } & $>35$ & $245(94.2)$ & $122(72.2)$ & $<0.001$ \\
\hline & $\leq 35$ & $15(5.8)$ & $47(27.8)$ & \\
\hline
\end{tabular}
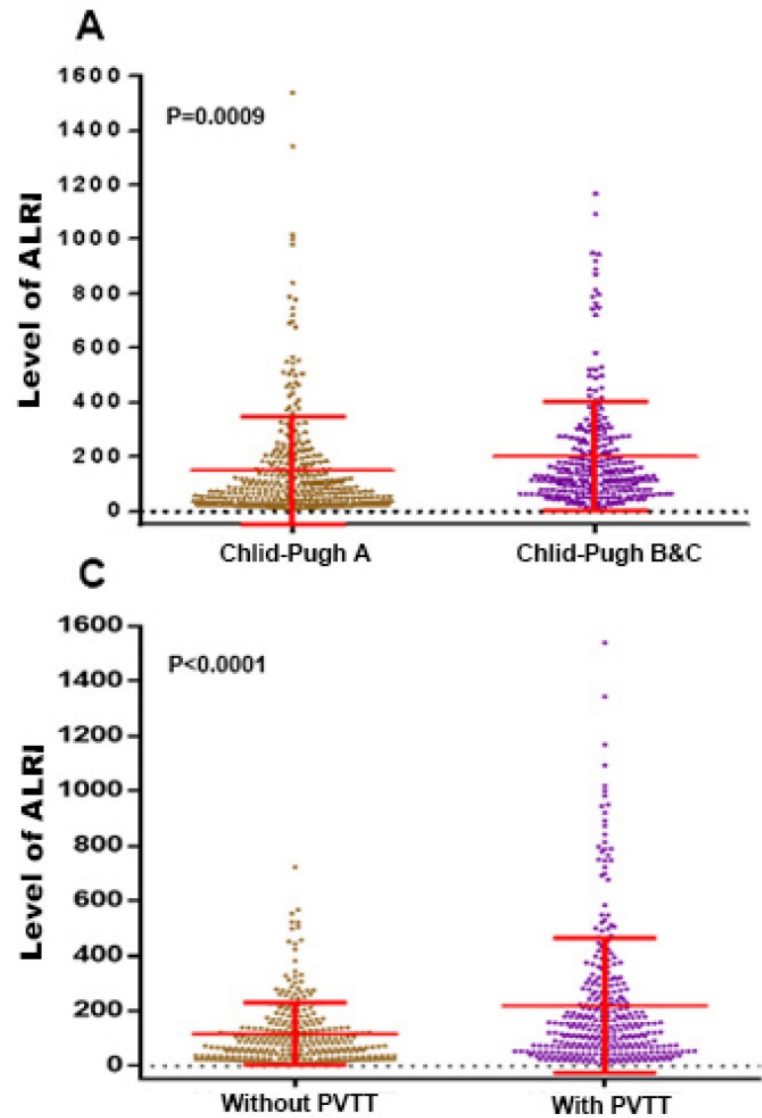

Figure 1. The levels of the ALRI were compared between subgroups characterised by: (A) Child-Pugh A vs. Child-Pugh B\&C; (B) ascites (without vs with); (C) PVTT (without vs with). ALRI: aspartate aminotransferase to lymphocyte ratio; PVTT: portal vein tumor thrombosis.

\begin{tabular}{|c|c|c|c|c|}
\hline \multirow[t]{3}{*}{ Variables } & & \multirow{2}{*}{$\begin{array}{l}\text { Group A } \\
\text { ALRI }>86.3\end{array}$} & \multirow{2}{*}{$\begin{array}{l}\text { Group B } \\
\text { ALRI } \leq 86.3\end{array}$} & \multirow[t]{3}{*}{$P$ value } \\
\hline & & & & \\
\hline & & $(n=260)$ & & \\
\hline \multirow[t]{2}{*}{$\mathrm{ALP}, \mathrm{U} / \mathrm{L}$} & $>200$ & $60(23.1 \%)$ & $9(5.3 \%)$ & $<0.001$ \\
\hline & $\leq 200$ & $200(76.9 \%)$ & $160(94.7 \%)$ & \\
\hline \multirow[t]{2}{*}{$\mathrm{AFP}, \mathrm{ng} / \mathrm{mL}$} & $>400$ & $128(49.2 \%)$ & $72(42.6 \%)$ & 0.198 \\
\hline & $\leq 400$ & $132(50.8 \%)$ & $97(57.4 \%)$ & \\
\hline \multirow[t]{2}{*}{ PVTT } & Yes & $146(56.2 \%)$ & $74(43.8 \%)$ & 0.014 \\
\hline & No & $114(43.8 \%)$ & $95(56.2 \%)$ & \\
\hline \multirow[t]{2}{*}{ SII } & $>376.4$ & 125(48.1\%) & $64(37.9 \%)$ & 0.046 \\
\hline & $\leq 376.4$ & $135(51.9 \%)$ & $105(62.1 \%)$ & \\
\hline \multirow[t]{2}{*}{ APRI } & $>1.37$ & $184(70.8 \%)$ & $58(34.3 \%)$ & $<0.001$ \\
\hline & $\leq 1.37$ & $76(29.2 \%)$ & $111(65.7 \%)$ & \\
\hline \multirow{4}{*}{ TNM stage } & I & $18(6.9 \%)$ & $16(9.4 \%)$ & 0.745 \\
\hline & II & $44(16.9 \%)$ & $29(17.2 \%)$ & \\
\hline & III & $127(48.8 \%)$ & $83(49.1 \%)$ & \\
\hline & IV & $71(27.4 \%)$ & $41(24.3 \%)$ & \\
\hline \multirow[t]{2}{*}{$\mathrm{T}$ category } & Т3-4 & $196(75.4)$ & $118(69.8)$ & 0.221 \\
\hline & T1-2 & $64(24.6)$ & $51(30.2)$ & \\
\hline \multirow[t]{2}{*}{ N category } & N0 & $209(80.4 \%)$ & $136(80.5 \%)$ & 1.000 \\
\hline & N1 & $51(19.6 \%)$ & $33(19.5 \%)$ & \\
\hline \multirow[t]{2}{*}{ M category } & M0 & $228(87.7 \%)$ & $155(91.7 \%)$ & 0.205 \\
\hline & M1 & $32(12.3 \%)$ & $14(8.3 \%)$ & \\
\hline \multirow[t]{3}{*}{ Child-Pugh grade } & A & $126(48.5 \%)$ & 127(75.1\%) & $<0.001$ \\
\hline & B & $110(42.3 \%)$ & $31(18.3 \%)$ & \\
\hline & C & $24(9.2 \%)$ & $11(6.6 \%)$ & \\
\hline
\end{tabular}

HGB: haemoglobin; BUN: blood urea nitrogen; ALB: albumin; TB: total bilirubin; AST: Aspartate Transaminase; ALP: alkaline phosphatase; AFP: alpha fetoprotein PVTT: portal vein tumor thrombosis; SII: systemic immune-inflammation index; APRI: aspartate aminotransferase to platelet count ratio index; ALRI: aspartate

aminotransferase to lymphocyte ratio; TNM: tumour-node-metastasis.

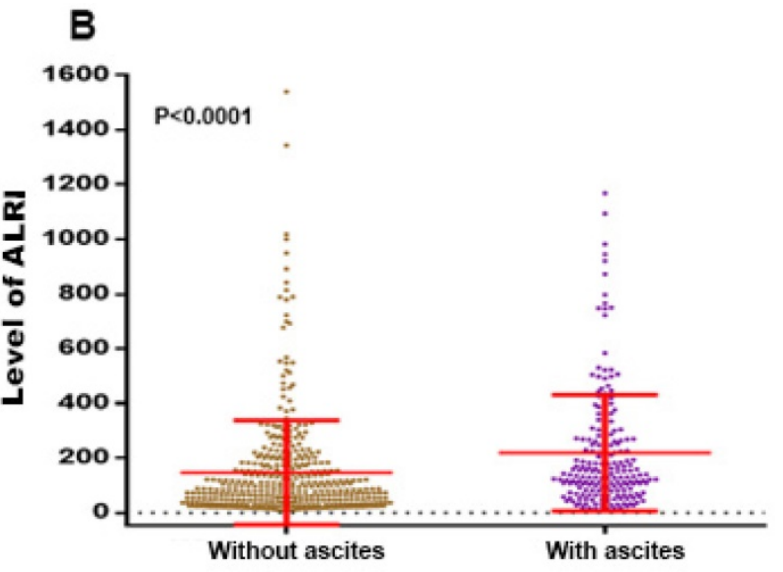




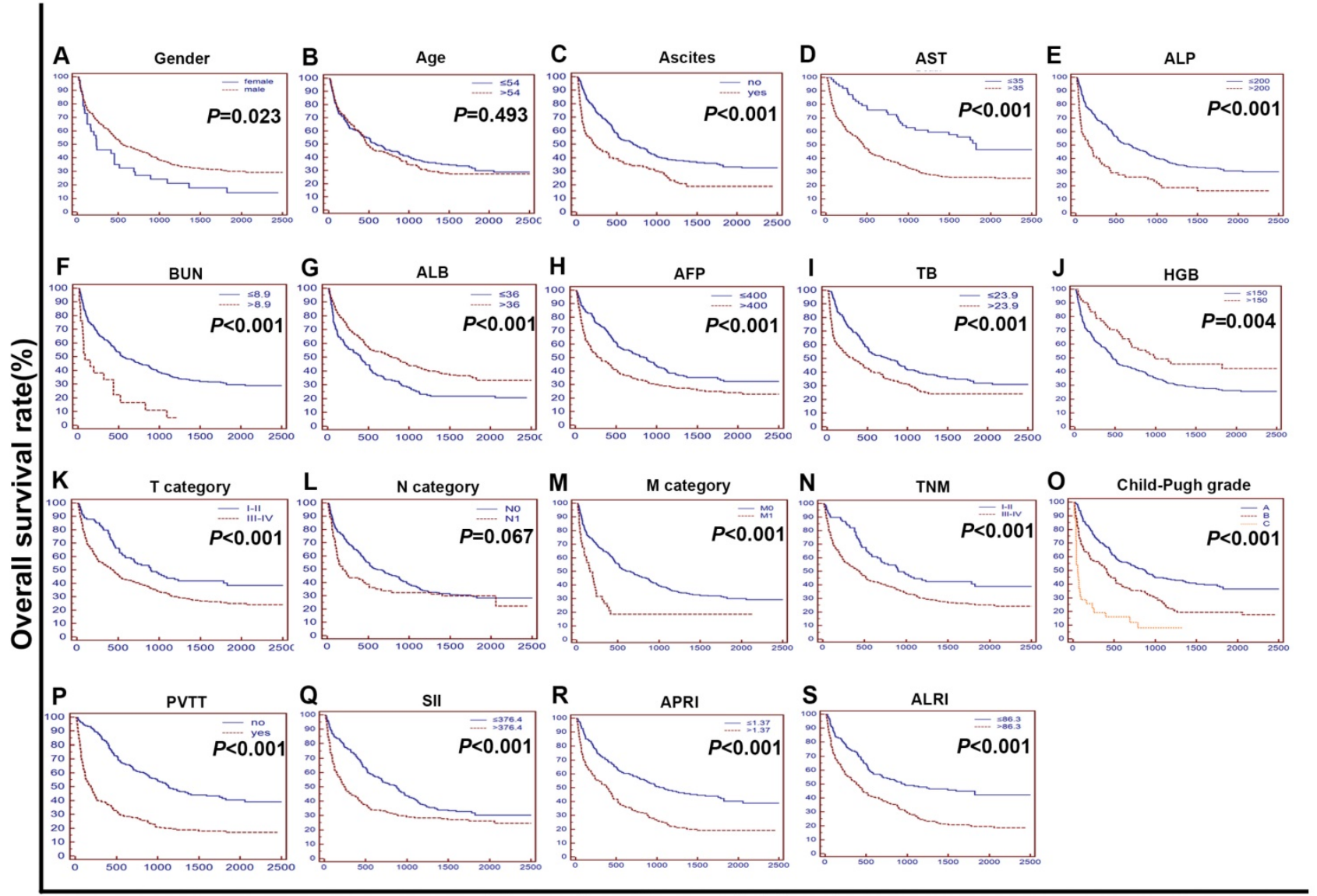

Time after diagnosis(days)

Figure 2. The Kaplan-Meier curves for overall survival (OS) were stratified by different features in the training cohort. The curves were stratified by gender (A), age (B), ascites (C), AST, U/L (D), ALP, U/L (E), BUN, mmol/L (F), ALB, g/L (G), AFP, ng/mL (H), TB, mmol/L (I), HGB, g/L (J), T category (AJCC 7th) (K), N category (AJCC 7th) (L), M category (AJCC 7th) (M), TNM (N) and Child-Pugh grade (O),PVTT (P),SII (R),APRI (S),ALRI (T). The OS was obviously different between subgroups stratified by ascites, AST, ALP, BUN, ALB, AFP, TB, HGB, T category, M category, TNM, Child-Pugh grade, PVTT, SII, APRI, ALRI ( $P<0.01)$. AST: Aspartate Transaminase; ALP: alkaline phosphatase; BUN: blood urea nitrogen; ALB: albumin; AFP: alpha fetoprotein; TB: total bilirubin; HGB: haemoglobin; AJCC: American Joint Committee on Cancer; N: node status. M: metastasis status. TNM: tumour-node-metastasis. PVTT: portal vein tumor thrombosis s; SIl: systemic immune inflammation index; APRI: aspartate aminotransferase to platelet count ratio index; ALRI: aspartate aminotransferase (AST) to lymphocyte ratio.

Table 3. The Chi-square analysis of the clinicopathologic variables between the high-ALRI and low-ALRI groups in the validation cohort I.

\begin{tabular}{|c|c|c|c|c|}
\hline \multicolumn{2}{|l|}{ Variables } & \multirow{2}{*}{$\begin{array}{l}\text { Group A } \\
\text { ALRI >86.3 }\end{array}$} & \multirow{2}{*}{$\begin{array}{l}\text { Group B } \\
\text { ALRI } \leq 86.3\end{array}$} & \multirow[t]{2}{*}{$P$ value } \\
\hline & & & & \\
\hline & & $(n=81)$ & $(n=88)$ & \\
\hline \multirow[t]{2}{*}{ Age, years } & $>54$ & $29(35.8 \%)$ & $44(50.0 \%)$ & 0.087 \\
\hline & $\leq 54$ & $52(64.2 \%)$ & $44(50.0 \%)$ & \\
\hline \multirow[t]{2}{*}{ Gender } & Male & $75(92.6 \%)$ & $12(13.6 \%)$ & 0.220 \\
\hline & Female & $6(7.4 \%)$ & $76(86.4 \%)$ & \\
\hline \multirow[t]{2}{*}{ Ascites } & Yes & $36(44.4 \%)$ & $25(28.4 \%)$ & 0.037 \\
\hline & No & $45(55.6 \%)$ & $63(71.6 \%)$ & \\
\hline \multicolumn{5}{|c|}{ Laboratory parameters (median/IQR) } \\
\hline \multirow[t]{2}{*}{$\mathrm{HGB}, \mathrm{g} / \mathrm{L}$} & $>150$ & $12(14.8 \%)$ & $13(14.8 \%)$ & 1.000 \\
\hline & $\leq 150$ & $69(85.2 \%)$ & $75(85.2 \%)$ & \\
\hline \multirow[t]{2}{*}{$\mathrm{BUN}, \mathrm{mmol} / \mathrm{L}$} & $>8.9$ & $12(14.8 \%)$ & $5(5.7 \%)$ & 0.071 \\
\hline & $\leq 8.9$ & $69(85.2 \%)$ & $83(94.3 \%)$ & \\
\hline \multirow[t]{2}{*}{ ALB, g/L } & $>36$ & $32(39.5 \%)$ & $48(54.5 \%)$ & 0.064 \\
\hline & $\leq 36$ & $49(60.5 \%)$ & $40(45.5 \%)$ & \\
\hline \multirow[t]{2}{*}{$\mathrm{TB}, \mathrm{mmol} / \mathrm{L}$} & $>23.9$ & $48(59.3 \%)$ & $22(25.0 \%)$ & $<0.001$ \\
\hline & $\leq 23.9$ & $33(40.7 \%)$ & $66(75.0 \%)$ & \\
\hline \multirow[t]{2}{*}{ AST, U/L } & $>35$ & $74(91.4)$ & $68(77.3)$ & 0.020 \\
\hline & $\leq 35$ & $7(8.6)$ & $20(22.7)$ & \\
\hline \multirow[t]{2}{*}{$\mathrm{ALP}, \mathrm{U} / \mathrm{L}$} & $>200$ & $37(45.7 \%)$ & $13(14.8 \%)$ & $<0.001$ \\
\hline & $\leq 200$ & $44(54.3 \%)$ & $75(85.2 \%)$ & \\
\hline $\mathrm{AFP}, \mathrm{ng} / \mathrm{mL}$ & $>400$ & $55(67.9 \%)$ & $40(45.5 \%)$ & 0.005 \\
\hline
\end{tabular}

\begin{tabular}{|c|c|c|c|c|}
\hline \multicolumn{2}{|l|}{ Variables } & \multirow{2}{*}{$\begin{array}{l}\text { Group A } \\
\text { ALRI }>86.3\end{array}$} & \multirow{2}{*}{$\begin{array}{l}\text { Group B } \\
\text { ALRI } \leq 86.3\end{array}$} & \multirow[t]{2}{*}{$P$ value } \\
\hline & & & & \\
\hline & & $(n=81)$ & $(n=88)$ & \\
\hline & $\leq 400$ & $26(32.1 \%)$ & $48(54.5 \%)$ & \\
\hline \multirow[t]{2}{*}{ PVTT } & Yes & $56(69.1 \%)$ & $40(45.5 \%)$ & 0.003 \\
\hline & No & $25(30.9 \%)$ & $48(54.5 \%)$ & \\
\hline \multirow[t]{2}{*}{ SII } & $>376.4$ & $73(90.1 \%)$ & $72(81.8 \%)$ & 0.185 \\
\hline & $\leq 376.4$ & $8(9.9 \%)$ & $16(18.2 \%)$ & \\
\hline \multirow[t]{2}{*}{ APRI } & $>1.37$ & $56(69.1 \%)$ & $23(26.1 \%)$ & $<0.001$ \\
\hline & $\leq 1.37$ & $25(30.9 \%)$ & $65(73.9 \%)$ & \\
\hline \multirow[t]{4}{*}{ TNM stage } & I & $2(2.5 \%)$ & $13(14.8 \%)$ & 0.026 \\
\hline & II & $5(6.2 \%)$ & $6(6.8 \%)$ & \\
\hline & III & $45(55.6 \%)$ & $37(42.0 \%)$ & \\
\hline & IV & $29(35.7 \%)$ & $32(36.4 \%)$ & \\
\hline \multirow[t]{2}{*}{ T category } & T3-4 & $72(88.9)$ & $68(77.3)$ & 0.065 \\
\hline & T1-2 & $9(11.1)$ & $20(22.7)$ & \\
\hline \multirow[t]{2}{*}{$\mathrm{N}$ category } & No & $60(74.1 \%)$ & $60(68.2 \%)$ & 0.498 \\
\hline & N1 & $21(25.9 \%)$ & $28(31.8 \%)$ & \\
\hline \multirow[t]{2}{*}{ M category } & M0 & $61(75.3 \%)$ & $76(86.4 \%)$ & 0.079 \\
\hline & M1 & $20(24.7 \%)$ & $12(13.6 \%)$ & \\
\hline \multirow[t]{3}{*}{ Child-Pugh grade } & A & $32(39.5 \%)$ & $57(64.8 \%)$ & 0.003 \\
\hline & B & $33(40.7 \%)$ & $24(27.2 \%)$ & \\
\hline & C & $16(19.8 \%)$ & $7(8.0 \%)$ & \\
\hline
\end{tabular}

HGB: haemoglobin; BUN: blood urea nitrogen; ALB: albumin; TB: total bilirubin; AST: aspartate Transaminase; ALP: alkaline phosphatase; AFP: alpha fetoprotein; PVTT: portal vein tumor thrombosis; SII: systemic immune-inflammation index; APRI: aspartate aminotransferase to platelet count ratio index; ALRI: aspartate aminotransferase to lymphocyte ratio; TNM: tumour-node-metastasis. 
In the validation cohort I, further research was done to test and verify the independent prognostic value of the ALRI, SII and APRI. In both univariate and multivariate analyses, ALRI has been determined as an independent prognostic factor for OS in this cohort $(\mathrm{HR}=1.511,95 \% \mathrm{CI}, 1.038$ to $2.199 ; P=0.032)$ (Table 5). SII was not a prognostic factor in the validation cohort I. APRI was a prognostic factor but not an independent prognostic factor of OS both in the training cohort and in the validation cohort I.

Table 4. Univariate and multivariate analyses of the prognostic factors for overall survival in $429 \mathrm{HCC}$ patients of the training cohort.

\begin{tabular}{|c|c|c|c|c|c|c|c|}
\hline \multirow[t]{2}{*}{ Variables } & \multicolumn{2}{|l|}{ Univariate } & \multicolumn{5}{|c|}{ Multivariate } \\
\hline & $\begin{array}{l}\text { Log-rank } \\
\chi^{2}\end{array}$ & $\begin{array}{l}P \\
\text { value }\end{array}$ & B & SE & HR & $95 \% \mathrm{CI}$ & $\begin{array}{l}P \\
\text { value }\end{array}$ \\
\hline Age, years $(>54 / \leq 54)$ & 0.470 & 0.493 & & & & & \\
\hline $\begin{array}{l}\text { Gender } \\
\text { (male/female) }\end{array}$ & 5.189 & 0.023 & -0.492 & 0.195 & 0.611 & 0.418 to 0.893 & 0.011 \\
\hline Ascites (yes/no) & 22.914 & $<0.001$ & & & & & \\
\hline \multicolumn{8}{|l|}{$\begin{array}{l}\text { Laboratory } \\
\text { parameters }\end{array}$} \\
\hline ALB, g/L $(>36 / \leq 36)$ & 14.929 & $<0.001$ & -0.299 & 0.128 & 0.7416 & 0.578 to 0.951 & 0.019 \\
\hline $\begin{array}{l}\mathrm{TB}, \mathrm{mmol} / \mathrm{L}(>23.9 / \leq \\
23.9)\end{array}$ & 15.167 & $<0.001$ & & & & & \\
\hline $\begin{array}{l}\mathrm{AFP}, \mathrm{ng} / \mathrm{mL}(>400 / \leq \\
400)\end{array}$ & 13.763 & $<0.001$ & & & & & \\
\hline 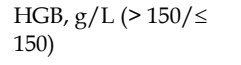 & 8.116 & 0.004 & & & & & \\
\hline $\begin{array}{l}\mathrm{BUN}, \mathrm{mmol} / \mathrm{L}(> \\
8.9 / \leq 8.9)\end{array}$ & 17.899 & $<0.001$ & 1.029 & 0.246 & 2.797 & 1.732 to 4.516 & $<0.001$ \\
\hline TNM (I-II/III-IV) & 12.988 & $<0.001$ & & & & & \\
\hline $\begin{array}{l}\text { T category } \\
\text { (T1-2/T3-4) }\end{array}$ & 12.319 & $<0.001$ & & & & & \\
\hline $\mathrm{N}$ category $(\mathrm{N} 0 / \mathrm{N} 1)$ & 3.346 & 0.067 & & & & & \\
\hline M category (M0/M1) & 19.952 & $<0.001$ & 0.375 & 0.193 & 1.455 & 0.998 to 2.119 & 0.052 \\
\hline PVTT (yes/no) & 68.849 & $<0.001$ & 0.888 & 0.127 & 2.4309 & 1.899 to 3.112 & $<0.001$ \\
\hline \multicolumn{8}{|l|}{ Child-Pugh grade } \\
\hline A & & & NA & NA & 1 & Reference & NA \\
\hline B & & & 0.379 & 0.136 & 1.461 & 1.122 to 1.903 & 0.005 \\
\hline $\mathrm{C}$ & & & 1.478 & 0.211 & 4.384 & 2.909 to 6.609 & $<0.001$ \\
\hline SII & 15.167 & $<0.001$ & 0.305 & 0.130 & 1.356 & 1.052to 1.749 & 0.020 \\
\hline ALRI $(>86.3 / \leq 86.3)$ & 28.442 & $<0.001$ & 0.393 & 0.135 & 1.481 & 1.138 to 1.927 & 0.004 \\
\hline APRI $(>1.37 / \leq 1.37)$ & 33.436 & $<0.001$ & 0.386 & 0.145 & 1.471 & 1.110 to 1.951 & 0.008 \\
\hline
\end{tabular}

We further validated the prognostic value of the ALRI, SII and APRI with two independent cohorts, the validation cohort II and the validation cohort III. In the validation cohort II, ALRI was identified as an independent prognostic factor for OS (HR $=3.166$, $95 \% \mathrm{CI}, 1.411$ to $7.103 ; P=0.005$ ) (table 8 ). SII was also identified as an independent prognostic factor. In the validation cohort III, ALRI was also identified as an independent prognostic factor for OS in this cohort $(\mathrm{HR}=3.921,95 \% \mathrm{CI}, 1.378$ to $11.158 ; P=0.010)$ (table 9).

Apart from ALRI, the following factors were confirmed as independent prognostic factors both in the training cohort and in the validation cohort I: BUN, PVTT and Child-Pugh grade.

\section{Comparison of the prognostic values of ALRI, AST and lymphocytes for HCC overall survival}

We compared the area under curves (AUCs) among AST, LYM and ALRI in predicting OS by ROC curves analysis in the training cohort and the validation cohort I. The AUC of the ALRI was obviously larger than that of the AST and LYM in the training cohort while the AUC of the ALRI was significantly larger than that of lymphocytes $(P<0.05)$ (Figure 4 and Supplemental Table 1).

Table 5. Univariate and multivariate analyses of the prognostic factors for overall survival in $169 \mathrm{HCC}$ patients of the validation cohort I.

\begin{tabular}{|c|c|c|c|c|c|c|c|}
\hline \multirow[t]{2}{*}{ Variables } & \multicolumn{2}{|l|}{ Univariate } & \multicolumn{5}{|c|}{ Multivariate } \\
\hline & $\begin{array}{l}\text { Log-rank } \\
\chi^{2}\end{array}$ & $\begin{array}{l}P \\
\text { value }\end{array}$ & B & SE & HR & $95 \% \mathrm{CI}$ & $\begin{array}{l}P \\
\text { value }\end{array}$ \\
\hline Age, years $(>54 / \leq 54)$ & 0.033 & 0.855 & & & & & \\
\hline Gender (male/female) & 0.178 & 0.673 & & & & & \\
\hline Ascites (yes/no) & 4.354 & 0.037 & & & & & \\
\hline \multicolumn{8}{|l|}{$\begin{array}{l}\text { Laboratory } \\
\text { parameters }\end{array}$} \\
\hline ALB, $g / L(>36 / \leq 36)$ & 5.970 & 0.015 & & & & & \\
\hline $\begin{array}{l}\mathrm{TB}, \mathrm{mmol} / \mathrm{L}(>23.9 / \leq \\
23.9)\end{array}$ & 8.017 & 0.005 & & & & & \\
\hline $\begin{array}{l}\mathrm{AFP}, \mathrm{ng} / \mathrm{mL}(>400 / \leq \\
400)\end{array}$ & 1.606 & 0.205 & & & & & \\
\hline $\begin{array}{l}\text { HGB, g/L (> 150/ } \\
150)\end{array}$ & 0.457 & 0.499 & & & & & \\
\hline $\begin{array}{l}\mathrm{BUN}, \mathrm{mmol} / \mathrm{L}(> \\
8.9 / \leq 8.9)\end{array}$ & 58.780 & $<0.001$ & 1.564 & 0.333 & 4.778 & 2.496 to 9.147 & $<0.001$ \\
\hline TNM (I-II/III-IV) & 1.833 & 0.176 & & & & & \\
\hline T category $(\mathrm{T} 1-2 / \mathrm{T} 3-4)$ & 1.224 & 0.269 & & & & & \\
\hline $\mathrm{N}$ category $(\mathrm{N} 0 / \mathrm{N} 1)$ & 3.188 & 0.074 & & & & & \\
\hline M category (M0/M1) & 11.684 & $<0.001$ & 0.493 & 0.215 & 1.637 & 1.076 to 2.491 & 0.022 \\
\hline PVTT (yes/no) & 20.441 & $<0.001$ & 0.593 & 0.184 & 1.810 & 1.265 to 2.590 & 0.001 \\
\hline \multicolumn{8}{|l|}{ Child-Pugh grade } \\
\hline A & & & NA & NA & 1 & Reference & NA \\
\hline B & & & NS & NS & 1 & Reference & NA \\
\hline $\mathrm{C}$ & & & 0.771 & 0.286 & 2.161 & 1.238 to 3.771 & 0.007 \\
\hline SII & 0.144 & 0.705 & & & & & \\
\hline ALRI $(>86.3 / \leq 86.3)$ & 19.229 & $<0.001$ & 0.413 & 0.193 & 1.511 & 1.038 to 2.199 & 0.032 \\
\hline APRI $(>1.37 / \leq 1.37)$ & 26.332 & $<0.001$ & 0.345 & 0.203 & 1.412 & 0.951 to 2.097 & 0.089 \\
\hline $\begin{array}{l}\text { HCC: hepatocellular ca } \\
\text { fetoprotein; HGB: haen } \\
\text { tumour-node-metastas } \\
\text { immune-inflammation } \\
\text { ratio; APRI: aspartate a }\end{array}$ & $\begin{array}{l}\text { cinoma } \\
\text { oglobin } \\
\text {; PVTT } \\
\text { ndex; A }\end{array}$ & $\begin{array}{l}\text { ALB: al } \\
\text { 3UN: b } \\
\text { yortal v } \\
\text { RI: asp }\end{array}$ & umin & $\begin{array}{l}\text { TB: tota } \\
\text { a nitro } \\
\text { or thror } \\
\text { minotra }\end{array}$ & $\begin{array}{l}\text { al biliru } \\
\text { gen; TI } \\
\text { mbosis } \\
\text { ansfera }\end{array}$ & $\begin{array}{l}\text { ubin; AFP: alp } \\
\text { NM: } \\
\text { is; SII: systemic } \\
\text { ase to lymphoc } \\
\text { index. }\end{array}$ & \\
\hline
\end{tabular}

Table 6. Comparisons of the ALRI, TNM and ALRI-TNM in the prognostic value for overall survival of $598 \mathrm{HCC}$ patients

\begin{tabular}{llll}
\hline Staging system & Likelihood ratio test & AIC & $\boldsymbol{P}$ value \\
& $\boldsymbol{\chi}^{\mathbf{2}}$ & & \\
\hline Nomogram & 233.93 & 4909.91 & $<0.0001$ \\
ALRI-TNM & 45.99 & 5080.15 & $<0.0001$ \\
ALRI & 30.75 & 5096.78 & $<0.0001$ \\
TNM & 21.86 & 5105.51 & $<0.0001$ \\
\hline
\end{tabular}

HCC: hepatocellular carcinoma; TNM: tumour-node-metastasis; ALRI: aspartate aminotransferase to lymphocyte ratio; AIC: Akaike information criterion. 


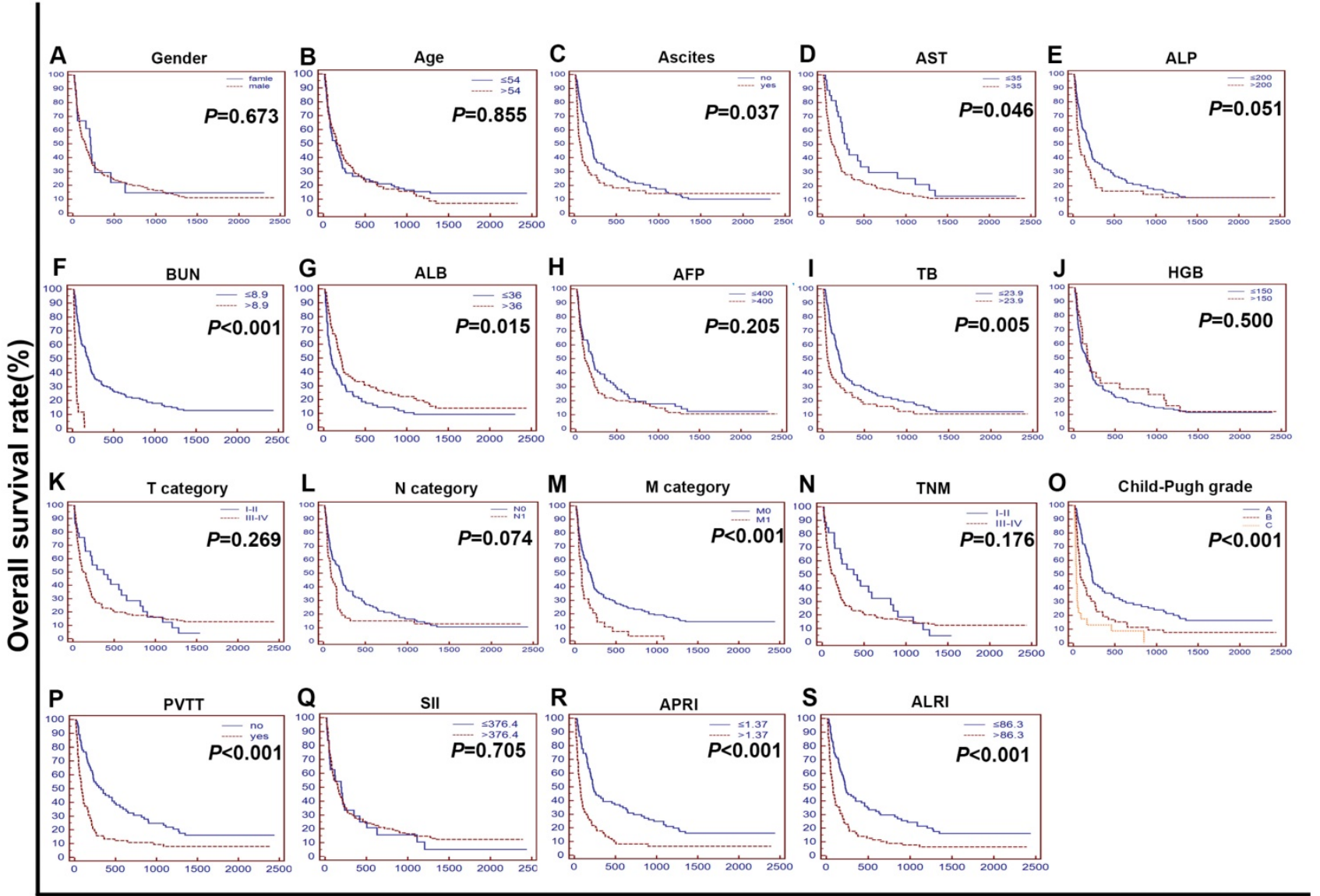

Time after diagnosis(days)

Figure 3. The Kaplan-Meier curves for overall survival (OS) were stratified by different features in validation cohort l. The curves were stratified by gender (A), age (B), ascites (C), AST, U/L (D), ALP, U/L (E), BUN, mmol/L (F), ALB, g/L (G), AFP, ng/mL (H), TB, mmol/L (I), HGB, g/L (J), T category (AJCC 7th) (K), N category (AJCC 7th) (L), M category (AJCC 7th) (M), TNM (N) and Child-Pugh grade (O),PVTT (P),SII (R),APRI (S),ALRI (T). The OS was obviously different between subgroups stratified by ascites, BUN, ALB, TB, M category, Child-Pugh grade, PVTT, APRI, ALRI $(P<0.01)$. AST: Aspartate Transaminase; ALP: alkaline phosphatase; BUN: blood urea nitrogen; ALB: albumin; AFP: alpha fetoprotein; TB: total bilirubin; HGB: haemoglobin; AJCC: American Joint Committee on Cancer; N: node status. M: metastasis status. TNM: tumour-node-metastasis. PVTT: portal vein tumor thrombosis; SIl: systemic immune-inflammation index; APRI: aspartate aminotransferase to platelet count ratio index; ALRI: aspartate aminotransferase (AST) to lymphocyte ratio

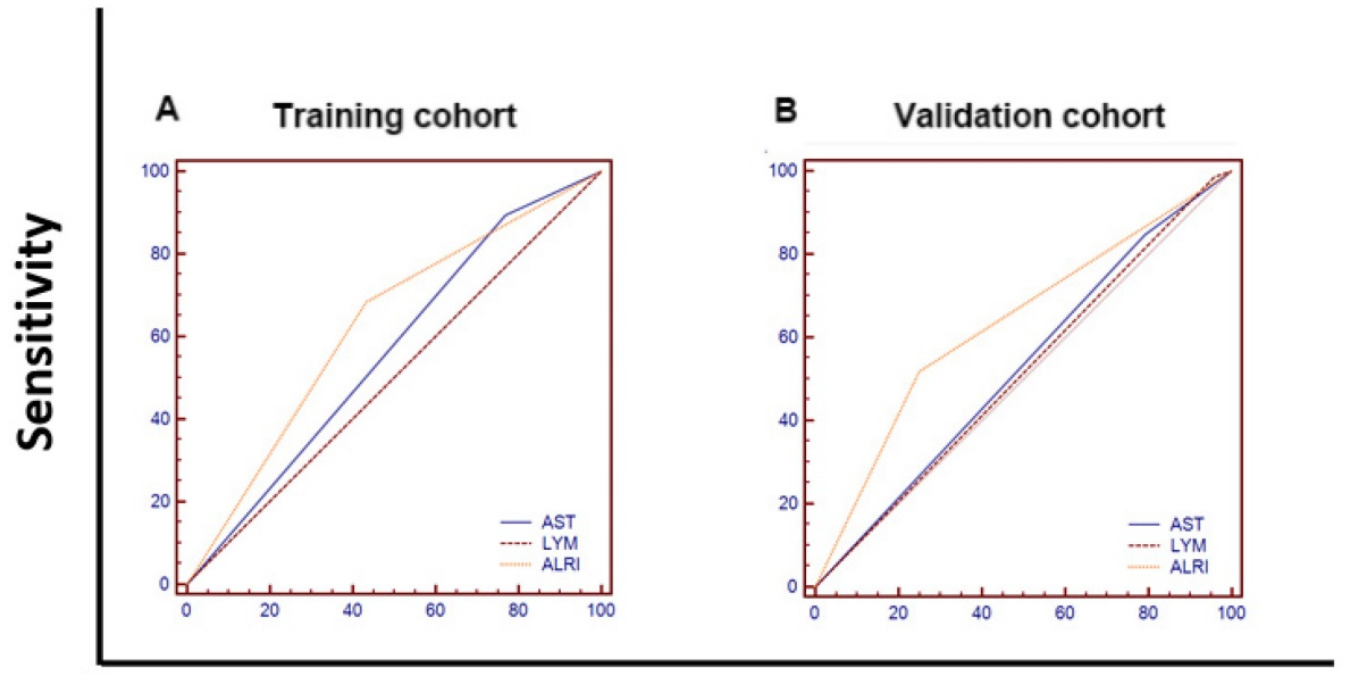

100-Specificity

Figure 4. The comparisons of the AUC values for survival status among AST, LYM and ALRI using ROC curves in the training cohort (A) and the validation cohort I (B). (A) The AUCs of ALRI, AST and LYM were $0.626,0.563$ and 0.502 , respectively. (B) The AUCs of ALRI, AST and LYM were $0.634,0.528$ and 0.514 , respectively. AST: aspartate aminotransferase; LYM: lymphocyte; ALRI: aspartate aminotransferase to lymphocyte ratio; ROC: receiver operating characteristic; AUC: area under curve. 
Table 7. Baseline demographics and clinical characteristics of the validation cohort II and III.

\begin{tabular}{|c|c|c|c|}
\hline \multicolumn{2}{|l|}{ Characteristics } & $\begin{array}{l}\text { Validation Cohort II, } \\
\mathrm{n}(\%)\end{array}$ & $\begin{array}{l}\text { Validation Cohort III, } \\
\mathrm{n}(\%)\end{array}$ \\
\hline \multicolumn{2}{|l|}{ Total } & $82(100)$ & $150(100)$ \\
\hline \multicolumn{2}{|c|}{ Age, years (median/IQR) } & $56(44-63)$ & $48(38-57)$ \\
\hline \multirow[t]{2}{*}{ Gender } & Male & $75(91.5)$ & $131(87.3)$ \\
\hline & Female & $7(8.5)$ & 19(12.7) \\
\hline \multirow[t]{2}{*}{ Ascites } & Yes & $12(14.6)$ & $24(16.0)$ \\
\hline & No & $70(85.4)$ & $126(84.0)$ \\
\hline \multicolumn{4}{|c|}{ Laboratory parameters (median/IQR) } \\
\hline \multicolumn{2}{|l|}{$\mathrm{HGB}, \mathrm{g} / \mathrm{L}$} & $136.50(123.00-147.00)$ & $142.00(129.75-150.25)$ \\
\hline \multicolumn{2}{|l|}{ GGT, U/L } & $96.00(60.00-144.75)$ & $49.50(32.00-86.00)$ \\
\hline \multicolumn{2}{|l|}{$\mathrm{ALB}, \mathrm{g} / \mathrm{L}$} & $38.05(33.13-41.53)$ & $41.85(39.25-44.53)$ \\
\hline \multicolumn{2}{|l|}{$\mathrm{TB}, \mathrm{mmol} / \mathrm{L}$} & $16.55(12.09-27.50)$ & $16.28(11.40-22.43)$ \\
\hline \multicolumn{2}{|l|}{$\mathrm{ALT}, \mathrm{U} / \mathrm{L}$} & $41.50(30.75-64.00)$ & $35.50(24.00-54.50)$ \\
\hline \multicolumn{2}{|l|}{ AST, U/L } & $47.00(31.75-72.00)$ & $38.50(28.00-65.25)$ \\
\hline \multicolumn{2}{|l|}{ ALP, U/L } & $105.00(81.75-147.50)$ & $73.00(60.00-97.00)$ \\
\hline \multicolumn{2}{|l|}{ PLT, U/L } & $147.50(89.75-203.00)$ & $164.00(111.50-206.25)$ \\
\hline \multirow[t]{2}{*}{$\mathrm{AFP}, \mathrm{ng} / \mathrm{mL}$} & $>400$ & $29(35.4)$ & $61(40.7)$ \\
\hline & $\leq 400$ & $53(64.6)$ & $89(59.3)$ \\
\hline \multirow[t]{2}{*}{ PVTT } & Yes & $15(18.3)$ & $22(14.7)$ \\
\hline & No & $67(81.7)$ & $128(85.3)$ \\
\hline \multirow[t]{3}{*}{ Child-Pugh grade } & A & $75(91.5)$ & $133(88.7)$ \\
\hline & $\mathrm{B}$ & $7(8.5)$ & $16(10.7)$ \\
\hline & $\mathrm{C}$ & $0(0)$ & $1(0.6)$ \\
\hline \multirow[t]{2}{*}{ SII } & $>376.4$ & $33(40.2)$ & $55(36.7)$ \\
\hline & $\leq 376.4$ & $49(59.8)$ & $95(63.3)$ \\
\hline \multirow[t]{2}{*}{ APRI } & $>1.37$ & $35(42.7)$ & $42(28.0)$ \\
\hline & $\leq 1.37$ & $47(57.3)$ & $108(72.0)$ \\
\hline \multirow[t]{2}{*}{ ALRI } & $>86.3$ & $11(13.4)$ & $17(11.3)$ \\
\hline & $\leq 86.3$ & $71(86.6)$ & 133(88.7) \\
\hline \multirow{2}{*}{$\begin{array}{l}\text { T category (AJCC } \\
7 \text { th) }\end{array}$} & T1-2 & $32(39.0)$ & $62(41.3)$ \\
\hline & T3-4 & $50(61.0)$ & $88(58.7)$ \\
\hline \multirow{2}{*}{$\begin{array}{l}\text { N category (AJCC } \\
7 \text { th) }\end{array}$} & No & 67(81.7) & $110(73.3)$ \\
\hline & N1 & $15(18.3)$ & $40(26.7)$ \\
\hline \multirow{2}{*}{$\begin{array}{l}\text { M category (AJCC } \\
7 \text { th) }\end{array}$} & M0 & $80(97.6)$ & $141(94.0)$ \\
\hline & M1 & $2(2.4)$ & $9(6.0)$ \\
\hline \multirow{4}{*}{$\begin{array}{l}\text { NCCN-TNM stage } \\
\text { (AJCC 7th) }\end{array}$} & I & $8(9.8)$ & $17(11.3)$ \\
\hline & II & $25(30.5)$ & $61(40.7)$ \\
\hline & III & $42(51.2)$ & $41(27.3)$ \\
\hline & IV & $7(8.5)$ & $31(20.7)$ \\
\hline
\end{tabular}

HGB: haemoglobin; GGT: glutamyl transpeptidase; ALB: albumin; TB: total bilirubin; ALT: alanine transaminase; AST: Aspartate Transaminase; ALP: alkaline phosphatase; PLT: platelet; AFP: alpha fetoprotein; PVTT: portal vein tumor thrombosis; SII: systemic immune-inflammation index; APRI: aspartate aminotransferase to platelet count ratio index; ALRI: aspartate aminotransferase to lymphocyte ratio; NCCN: The National Comprehensive Cancer Network; AJCC: The American Joint Committee on Cancer; TNM: tumour-node-metastasis.

Table 8. Univariate and multivariate analyses of the prognostic factors for overall survival in $82 \mathrm{HCC}$ patients of the validation cohort II.

\begin{tabular}{|c|c|c|c|c|c|c|c|}
\hline \multirow[t]{2}{*}{ Variables } & \multicolumn{2}{|c|}{ Univariate } & \multicolumn{5}{|c|}{ Multivariate } \\
\hline & $\begin{array}{l}\text { Log-rank } \\
\chi 2\end{array}$ & $\begin{array}{l}P \\
\text { value }\end{array}$ & B & SE & HR & $95 \% \mathrm{CI}$ & $\begin{array}{l}P \\
\text { value }\end{array}$ \\
\hline Age, years $(>54 / \leq 54)$ & 0.050 & 0.823 & & & & & \\
\hline Gender (male/female) & 0.633 & 0.426 & & & & & \\
\hline Ascites (yes/no) & 4.172 & 0.041 & 1.046 & 0.369 & 2.845 & 1.387 to 5.837 & 0.005 \\
\hline \multicolumn{8}{|l|}{$\begin{array}{l}\text { Laboratory } \\
\text { parameters }\end{array}$} \\
\hline $\mathrm{ALB}, \mathrm{g} / \mathrm{L}(>36 / \leq 36)$ & 0.102 & 0.749 & & & & & \\
\hline $\begin{array}{l}\mathrm{TB}, \mathrm{mmol} / \mathrm{L}(>23.9 / \leq \\
23.9)\end{array}$ & 1.788 & 0.181 & & & & & \\
\hline $\begin{array}{l}\mathrm{AFP}, \mathrm{ng} / \mathrm{mL}(>400 / \leq \\
400)\end{array}$ & 10.531 & 0.001 & 0.798 & 0.281 & 2.221 & 1.285 to 3.839 & 0.005 \\
\hline $\begin{array}{l}\text { HGB, g/L (> 150/ } \\
150)\end{array}$ & 0.123 & 0.726 & & & & & \\
\hline TNM (I-II/III-IV) & 13.449 & $<0.001$ & & & & & \\
\hline
\end{tabular}

\begin{tabular}{|c|c|c|c|c|c|c|c|}
\hline \multirow[t]{2}{*}{ Variables } & \multicolumn{2}{|c|}{ Univariate } & \multicolumn{5}{|c|}{ Multivariate } \\
\hline & $\begin{array}{l}\text { Log-rank } \\
\chi^{2}\end{array}$ & $\begin{array}{l}P \\
\text { value }\end{array}$ & B & SE & $\mathrm{HR}$ & $95 \% \mathrm{CI}$ & $\begin{array}{l}P \\
\text { value }\end{array}$ \\
\hline T category (T1-2/T3-4) & 10.692 & 0.001 & & & & & \\
\hline $\mathrm{N}$ category (N0/N1) & 14.091 & $<0.001$ & & & & & \\
\hline M category (M0/M1) & 24.740 & $<0.001$ & & & & & \\
\hline PVTT (yes/no) & 12.067 & 0.001 & 1.002 & 0.350 & 2.724 & 1.378 to 5.384 & 0.004 \\
\hline \multicolumn{8}{|l|}{ Child-Pugh grade } \\
\hline \multicolumn{8}{|l|}{ A } \\
\hline B & 0.417 & 0.519 & & & & & \\
\hline \multicolumn{8}{|l|}{ C } \\
\hline SII & 9.706 & 0.002 & 0.985 & 0.312 & 2.678 & 1.457 to 4.920 & 0.002 \\
\hline ALRI $(>86.3 / \leq 86.3)$ & 15.393 & $<0.001$ & 1.152 & 0.415 & 3.166 & 1.411 to 7.103 & 0.005 \\
\hline APRI (> 1.37/ $\leq 1.37)$ & 0.702 & 0.402 & & & & & \\
\hline $\begin{array}{l}\text { HCC: hepatocellular } \\
\text { fetoprotein; HGB: ha } \\
\text { tumor thrombosis; SI } \\
\text { aminotransferase to } 1\end{array}$ & $\begin{array}{l}\text { inom } \\
\text { globi } \\
\text { stemi } \\
\text { phocy }\end{array}$ & $\begin{array}{l}\text { ALB: al } \\
\text { CNM: } t \\
\text { nmun } \\
\text { atio; A }\end{array}$ & $\operatorname{mir}$ & B: tc & bil & $\begin{array}{l}\text { ubin; AFP: a } \\
\text { sis; PVTT: p } \\
\text {; ALRI: aspa } \\
\text { transferase }\end{array}$ & $\begin{array}{l}\text { ha } \\
\text { tal veir } \\
\text { ate }\end{array}$ \\
\hline
\end{tabular}

Table 9. Univariate and multivariate analyses of the prognostic factors for overall survival in $150 \mathrm{HCC}$ patients of the validation cohort III.

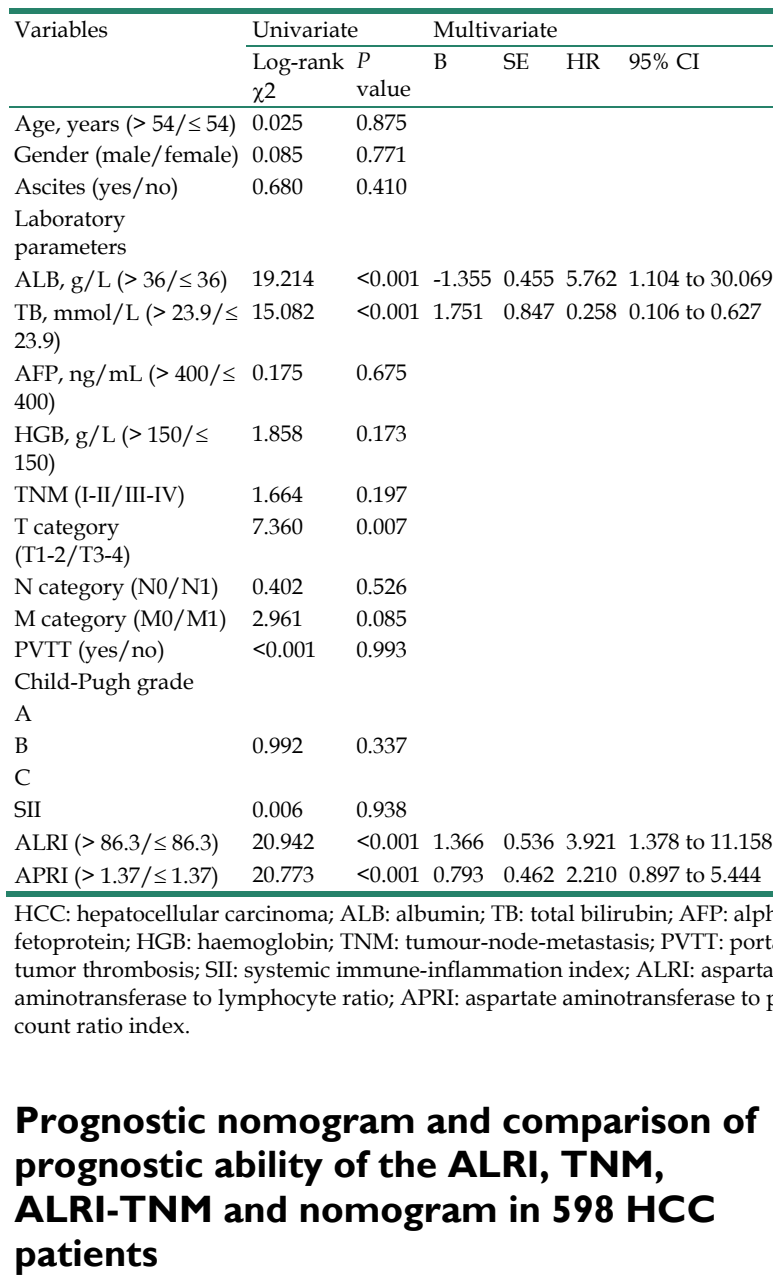

To further create a more accurate prediction model, we established a prognostic nomogram including ALRI, PVTT, distant metastasis, Child-Pugh grade and BUN in the training cohort and then verified the nomogram in the validation cohort I (Figure 5). In the training cohort, the C-index for OS prediction with the formulated nomogram was 0.722 
and the C-index was also 0.722 in the validation cohort I. The C-index between those two cohorts exhibited optimal consistency. To improve the prognostic ability of the TNM, we integrated the ALRI into the TNM to establish the ALRI-TNM system. In 598 HCC patients, we compared the prognostic ability of the ALRI, TNM, ALRI-TNM and nomogram. The AUC of the Nomogram was the largest when predicting 3-month, 6-month, 1-year and 2-year survival among the four systems, followed by the ALRI-TNM $(P<0.05)$ (Figure 6 and Supplemental Table 2). When predicting OS, the likelihood ratio test (LRT) suggested that the Nomogram had the largest $X^{2}$ and the smallest Akaike information criterion (AIC) values $(P<0.0001)$. The prognostic nomogram was the best in predicting 3-month, 6-month, 1-year, 2 -year survival and OS among the four systems (Table $6)$.

\section{Discussion}

Most HCC patients are diagnosed at advanced stage and the OS of untreated advanced HCC patients ranges from 3 to 6 months. Most advanced HCC patients need palliative treatments to prolong the OS, reduce the suffering and improve quality of life [20].It is important for us to assess the prognosis of HCC patients with palliative treatments more accurately to make more precise prognostic stratification and make individualized treatments. Currently, in clinical practice, methods for assessing prognosis include PET-CT, CT, MRI, DSA, ultrasonography and AFP, etc. However, the accurate prognosis prediction of HCC is not satisfactory. Many studies are still searching for novel independent prognostic factors and serum markers are one of the best candidates. Emerging studies have showed that inflammation related factors and immune-related factors is possible prognostic factors of HCC patients with palliative treatments [13]. For example, NLR has been recently confirmed as an independent prognostic factor of in HCC patients who received sorafenib and in HCC patients who received immune checkpoint inhibitor. Lymphocytes were very important in host anticancer immune responses and influence prognosis of HCC, the same goes for liver function. Serum factors reflecting lymphocyte counts, liver function, inflammation and immune status may be novel prognostic factors of HCC patients. Only a few articles have focused on the prognostic value of ALRI, SII and APRI in HCC patients, these articles have the following shortcomings. Most of the published articles only focused on the independent prognostic

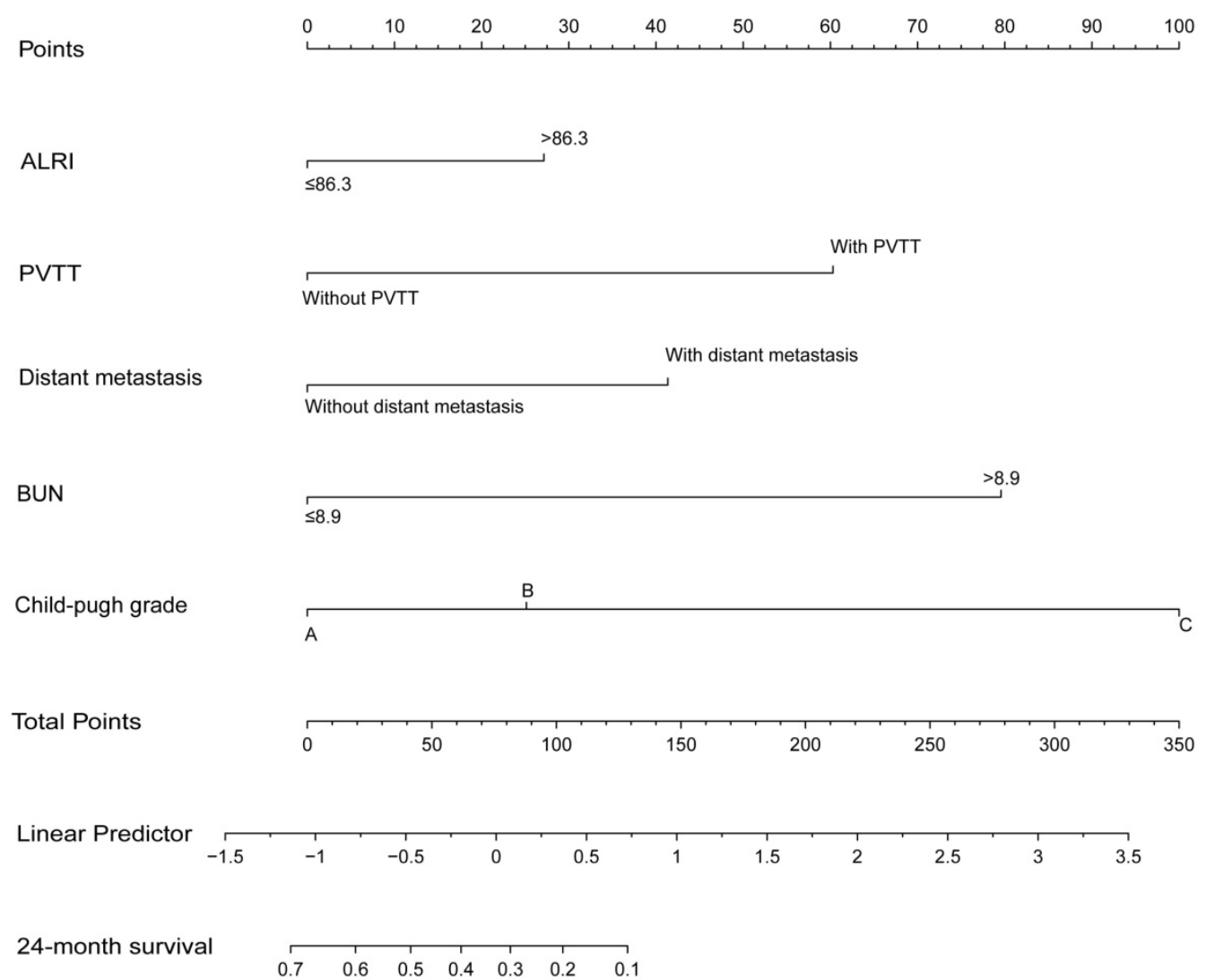

Figure 5. The prognostic nomogram for HCC patients treated with palliative treatments in our study. ALRI: aspartate aminotransferase to lymphocyte ratio; PVTT: portal vein tumor thrombus; BUN: blood urea nitrogen; OS: overall survival; HCC: hepatocellular carcinoma. 


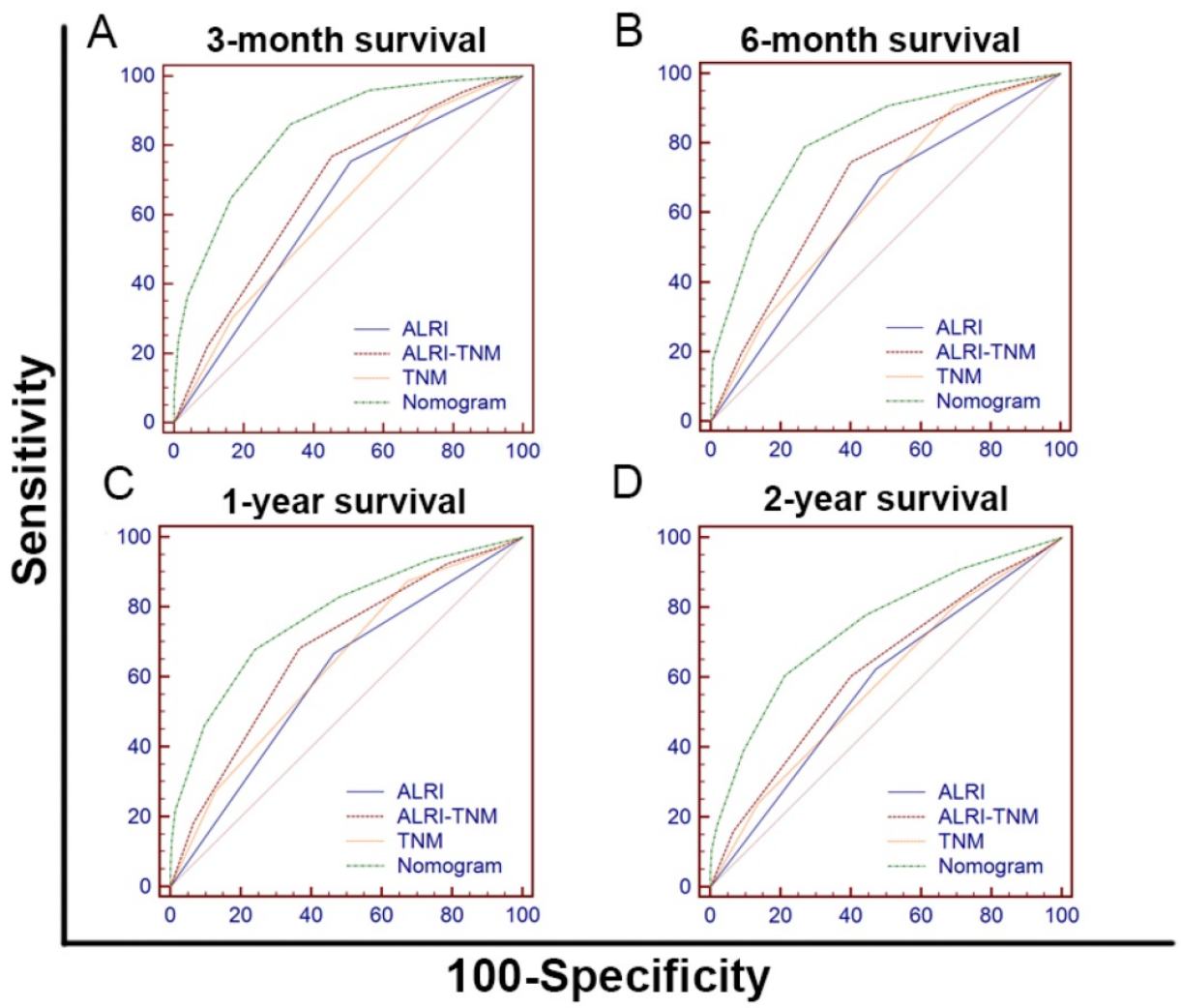

Figure 6. ROC curves of the ALRI, ALRI-TNM, TNM and Nomogram for predicting 3-month(A),6-month(B), 1 -year(C) and 2-year(D) survival in 598 HCC patients. (A) The AUCs of the Nomogram, ALRI-TNM, TNM and ALRI were $0.840,0.679,0.619$ and 0.624 , respectively. (B) The AUCs of the Nomogram, ALRI-TNM, TNM and ALRI were 0.814 , $0.688,0.637$ and 0.610 , respectively. (C) The AUCs of the Nomogram, ALRI-TNM, TNM and ALRI were $0.774,0.679,0.635$ and 0.601 , respectively. (D) The AUCs of the Nomogram, ALRI-TNM, TNM and ALRI were $0.745,0.620,0.584$ and 0.576 , respectively. ALRI: aspartate aminotransferase to lymphocyte ratio; TNM: tumor-node-metastasis, ROC: receiver operating characteristic.

value of ALRI for a specific cohort of HCC patients, such as HCC patients undergoing TACE or curative resection. The number of patients of these published articles is relatively small, ranging from 189 to 371 . The researchers also did not explore the prognostic values of ALRI, SII and APRI in the same study [17-21]. Furthermore, all the published articles focused on the prognostic value of ALRI were only internally validated, without validation of independent cohorts.

Here we conducted a study exploring the independent prognostic value of ALRI in 830 HCC patients, taking SII and APRI into account at the same time. The independent prognostic value of ALRI was identified in the training cohort of 429 HCC patients, validated in the validation cohort I of 169 HCC patients, further validated in the validation cohort of 82 HCC patients treated with TACE and in the validation cohort of $150 \mathrm{HCC}$ patients treated with curative resection. The large number of patients and the independent validation cohorts make our conclusions more reliable.

Elevated preoperative aspartate ALRI was reported to be as an independent prognostic factor for patients with HCC after curative surgery and after TACE $[17,21]$. Postoperative ALRI change was also reported to be an independent predictor of survival in patients with small hepatocellular carcinoma with curative treatments [18]. However, the sample size of these studies was relatively small and the prognostic value of ALRI in HCC patients with palliative treatments was not well confirmed. To the best of our knowledge, our study for the first time confirmed the ALRI as a novel independent prognostic index for HCC patients with palliative treatments in a large cohort of 598 HCC patients. Serum level of AST is a commonly used indicator reflecting damage of liver function. Increase of AST may also reflect the increase of HBV copy number and progression of tumor. The level of lymphocytes in HCC patients is often higher than that of healthy people, and lymphocytes are responsible for immune response to viral infections and tumor cells [22]. Lymphocytes were reported to play central role in fighting against tumor and lymphocytes infiltration in mouse models were prognostic of survival outcome. As immune check point inhibitors had been approved for advanced HCC patients recently and ALRI was an index reflecting immune status and liver function [23], it is interesting to explore the prognostic value of ALRI in HCC patients treated with immune check point inhibitors. 
The systemic immune-inflammation index (SII) had been reported to be a prognostic index for HCC and gastric patients after curative surgery $[17,19,24]$. The prognostic value of SII in HCC patients with palliative treatments was not reported. SII is a parameter that reflects the ratio of platelets, neutrophils and lymphocytes as previously described $[19,25]$. A study of 133 patients with liver cancer surgery found that SII was distinctly associated with poor prognosis in patients with primary liver cancer. SII was confirmed as an independent prognostic factor of OS in the training cohort. HCC patients with high SII had a poorer prognosis than that of HCC patients with low SII. One of the possible explanations for the increase in SII levels is the relative decrease in lymphocytes. Lymphocytes mediate cytotoxic cell death, inhibit tumor cell proliferation and metastasis, and play an important role in host anti-tumor immunity. A decrease in the number of lymphocytes leads to a decrease in lymphocyte-dependent anti-tumor ability and a higher risk of tumor recurrence and metastasis. Another reason for the increase in SII levels is the increase in platelet and neutrophil counts. Elevated platelet counts promote the release of platelet-derived angiogenic factors in tumor micro-vessels, which are important mediators of tumor growth [26]; neutrophils can secrete lots of vascular endothelial growth factor (VEGF) and accelerate the generation of tumor blood vessels, promote tumor growth and metastasis [27].Therefore, patients with high SII ratios are often in an unbalanced state of anti-tumor inflammatory response, and the inflammatory response evolves in the direction of promoting tumor formation and metastasis, resulting in poor patient prognosis.

APRI was identified as a simple noninvasive index which can predict both significant fibrosis and cirrhosis in patients with chronic hepatitis C [28]. Studies have suggested that APRI has a strong correlation with liver histopathological findings. As liver fibrosis and cirrhosis are crucial factors for development of HCC, APRI had also been reported to be as an independent prognostic factor in HCC patients with curative resection and radiofrequency ablation [29]. Combining NLR and APRI may improve the prognostic accuracy in HCC patients after surgical resection. However, APRI was a prognostic factor but not an independent prognostic factor of OS both in the training cohort and in the validation cohort I. APRI was inferior to ALRI in prediction in OS of HCC patients with palliative treatments.

TNM staging system is a commonly used staging system for HCC in clinical practice. However, the disadvantages of TNM staging system are obvious. It does not include indicators reflecting liver function, immune function or inflammation status, prognostic value of TNM may be further improved by incorporating these factors. Interestingly, ALRI-TNM had better prognostic ability of TNM in predicting 3-month, 6-month, 1-year, 2-year survival and OS. The incorporation of ALRI into TNM logically refined the predictive accuracy and improved the performance of prediction of TNM in terms of increase of corresponding AUCs. Furthermore, we for the first time established a prognostic nomogram including ALRI. The prognostic nomogram turned out to be the best in predicting 3-month, 6-month, 1-year, 2-year survival and OS among TNM, ALRI, ALRI-TNM and nomogram. ALRI enlightened the predictive value of conventional factors in the prognostic nomogram in HCC patients with palliative treatments. The prognostic nomogram including ALRI resulted in better prognostic ability. Last but not least, the ALRI is from serum examinations, indicating ALRI is easy to get, convenient and cheap.

Several limitations should be considered as follows. First, our study was essentially a retrospective study and all the data was retrospectively reviewed from a single center in China. A larger cohort and multicenter prospective study should be conducted to verify our results. Second, the cutoff value used in our study might not be suitable for other studies. Prospective validation or a meta-analysis of various studies focused on ALRI is needed to further confirm the most suitable cutoff value of ALRI. Third, the prognostic value of the dynamic change of ALRI in HCC patients with palliative treatments might be needed to further clarified.

In conclusion, the ALRI was a novel independent prognostic index for the HCC patients treated with palliative treatments.

\section{Supplementary Material}

Supplementary tables.

http://www.jcancer.org/v10p2299s1.pdf

\section{Abbreviations}

ALRI: aspartate aminotransferase to lymphocyte ratio; SII: systemic immune-inflammation index; APRI: aspartate aminotransferase to platelet count ratio index; HCC: hepatocellular carcinoma; HGB: hemoglobin; GGT: glutamyl transpeptidase; BUN: blood urea nitrogen; ALB: albumin; TB: total bilirubin; ALT: alanine transaminase; AST: Aspartate Transaminase; ALP: alkaline phosphatase; PLT: platelet; AFP: alpha fetoprotein; PVTT: portal vein tumor thrombosis; NCCN: The National Comprehensive Cancer Network; AJCC: The 
American Joint Committee on Cancer; TNM: tumor-node-metastasis; OS: overall survival; ROC: receiver operating characteristic; AUC: area under curve.

\section{Acknowledgements}

This study was supported by grants from the National Natural Science Foundation of China (grant no. 81502271, 31600710 and 81372374), the Combination Project of Production, the Scientific Research Project for University belonging to Guangzhou Municipal (grant no. 1201630019), China Postdoctoral Science Foundation Grant(2018M643301, 2018M643340), the Natural Science Foundation of Guangdong (grant no. 2018A0303130282, 2017A030313537, 2016A030313302, 2014A030312015 and 2014A030313146), the Project on the Integration of Industry, Education and Research of Guangdong Province (grant no. 2012B091100460) and the Medical Scientific Research Foundation of Guangdong Province (grant no. A2015109).

\section{Competing Interests}

The authors have declared that no competing interest exists.

\section{References}

1. El-Serag HB, Rudolph KL. Hepatocellular carcinoma: epidemiology and molecular carcinogenesis. Gastroenterology. 2007; 132: 2557-76.

2. Jemal A, Bray F, Center MM, Ferlay J, Ward E, Forman D. Global cancer statistics. CA: a cancer journal for clinicians. 2011; 61: 69-90.

3. Xu RH, Wei W, Krawczyk M, Wang W, Luo H, Flagg K, et al. Circulating tumour DNA methylation markers for diagnosis and prognosis of hepatocellular carcinoma. Nature materials. 2017; 16: 1155-61.

4. Chen W, Zheng R, Baade PD, Zhang S, Zeng H, Bray F, et al. Cancer statistics in China, 2015. CA: a cancer journal for clinicians. 2016; 66: 115-32.

5. Llovet JM, Zucman-Rossi J, Pikarsky E, Sangro B, Schwartz M, Sherman M, et al. Hepatocellular carcinoma. Nature reviews Disease primers. 2016; 2: 16018.

6. Bruix J, Sherman M. Management of hepatocellular carcinoma: an update. Hepatology (Baltimore, Md). 2011; 53: 1020-2.

7. Lemoine M, Shimakawa Y, Nayagam S, Khalil M, Suso P, Lloyd J, et al. The gamma-glutamyl transpeptidase to platelet ratio (GPR) predicts significant liver fibrosis and cirrhosis in patients with chronic HBV infection in West Africa. Gut. 2016; 65: 1369-76.

8. Wang RQ, Zhang QS, Zhao SX, Niu XM, Du JH, Du HJ, et al. Gamma-glutamyl transpeptidase to platelet ratio index is a good noninvasive biomarker for predicting liver fibrosis in Chinese chronic hepatitis B patients. The Journal of international medical research. 2016; 44: 1302-13.

9. Hu YC, Liu H, Liu XY, Ma LN, Guan YH, Luo $X$, et al. Value of gamma-glutamyltranspeptidase-to-platelet ratio in diagnosis of hepatic fibrosis in patients with chronic hepatitis B. World journal of gastroenterology. 2017; 23: 7425-32.

10. Llovet JM, Bru C, Bruix J. Prognosis of hepatocellular carcinoma: the BCLC staging classification. Seminars in liver disease. 1999; 19: 329-38.

11. Llovet JM, Bruix J. Prospective validation of the Cancer of the Liver Italian Program (CLIP) score: a new prognostic system for patients with cirrhosis and hepatocellular carcinoma. Hepatology (Baltimore, Md). 2000; 32: 679-80.

12. Cai XR, Chen ZH, Liu MM, Lin JX, Zhang XP, Chen J, et al. Modified CLIP score with the albumin-bilirubin grade retains prognostic value in HBV-related hepatocellular carcinoma patients treated with trans-catheter arterial chemoembolization therapy. Journal of Cancer. 2018; 9: 2380-8.

13. Sun B, Karin M. Obesity, inflammation, and liver cancer. Journal of hepatology. 2012; 56: 704-13.

14. Hong YF, Chen ZH, Wei L, Ma XK, Li X, Wen JY, et al. Identification of the prognostic value of lymphocyte-to-monocyte ratio in patients with HBV-associated advanced hepatocellular carcinoma. Oncology letters. 2017; 14: 2089-96.

15. Elinav E, Nowarski $\mathrm{R}$, Thaiss $\mathrm{CA}, \mathrm{Hu}$ B, Jin $\mathrm{C}$, Flavell RA. Inflammation-induced cancer: crosstalk between tumours, immune cells and microorganisms. Nature reviews Cancer. 2013; 13: 759-71.
16. Dirican A, Ekinci N, Avci A, Akyol M, Alacacioglu A, Kucukzeybek Y, et al. The effects of hematological parameters and tumor-infiltrating lymphocytes on prognosis in patients with gastric cancer. Cancer biomarkers : section A of Disease markers. 2013; 13: 11-20.

17. Yang Z, Zhang J, Lu Y, Xu Q, Tang B, Wang Q, et al. Aspartate aminotransferase-lymphocyte ratio index and systemic immune-inflammation index predict overall survival in HBV-related hepatocellular carcinoma patients after transcatheter arterial chemoembolization. Oncotarget. 2015; 6: 43090-8.

18. Jin J, Zhu P, Liao Y, Li J, Liao W, He S. Elevated preoperative aspartate aminotransferase to lymphocyte ratio index as an independent prognostic factor for patients with hepatocellular carcinoma after hepatic resection. Oncotarget. 2015; 6: 19217-27.

19. $\mathrm{Hu}$ B, Yang $\mathrm{XR}, \mathrm{Xu}$ Y, Sun YF, Sun C, Guo W, et al. Systemic immune-inflammation index predicts prognosis of patients after curative resection for hepatocellular carcinoma. Clinical cancer research : an official journal of the American Association for Cancer Research. 2014; 20: 6212-22.

20. Poon RT, Fan ST, Lo CM, Liu CL, Wong J. Long-term survival and pattern of recurrence after resection of small hepatocellular carcinoma in patients with preserved liver function: implications for a strategy of salvage transplantation. Annals of surgery. 2002; 235: 373-82

21. He C, Peng W, Li C, Wen TF. Postoperative aspartate aminotransferase to lymphocyte ratio index change is an independent predictor of survival in patients with small hepatocellular carcinoma. Medicine. 2017; 96: e8540.

22. van Beek JH, de Moor MH, de Geus EJ, Lubke GH, Vink JM, Willemsen G, et al. The genetic architecture of liver enzyme levels: GGT, ALT and AST. Behavior genetics. 2013; 43: 329-39.

23. Min YN, Wang CY, Li XX, Hou Y, Qiu JH, Ma J, et al. Participation of B-cell-activating factor receptors in the pathogenesis of immune thrombocytopenia. Journal of thrombosis and haemostasis : JTH. 2016; 14: 559-71.

24. Liu X, Sun X, Liu J, Kong P, Chen S, Zhan Y, et al. Preoperative C-Reactive Protein/Albumin Ratio Predicts Prognosis of Patients after Curative Resection for Gastric Cancer. Translational oncology. 2015; 8: 339-45.

25. Wang BL, Tian L, Gao XH, Ma XL, Wu J, Zhang CY, et al. Dynamic change of the systemic immune inflammation index predicts the prognosis of patients with hepatocellular carcinoma after curative resection. Clinical chemistry and laboratory medicine. 2016; 54: 1963-9.

26. Sierko E, Wojtukiewicz MZ. Platelets and angiogenesis in malignancy. Seminars in thrombosis and hemostasis. 2004; 30: 95-108.

27. Feng JF, Huang Y, Chen QX. Preoperative platelet lymphocyte ratio (PLR) is superior to neutrophil lymphocyte ratio (NLR) as a predictive factor in patients with esophageal squamous cell carcinoma. World journal of surgical oncology. 2014; 12: 58.

28. Wai CT, Greenson JK, Fontana RJ, Kalbfleisch JD, Marrero JA, Conjeevaram HS, et al. A simple noninvasive index can predict both significant fibrosis and cirrhosis in patients with chronic hepatitis C. Hepatology (Baltimore, Md). 2003; 38: 518-26.

29. Peng W, Li C, Wen TF, Yan LN, Li B, Wang WT, et al. Postoperative aspartate aminotransferase to platelet ratio index change predicts prognosis for hepatocellular carcinoma. Medicine. 2016; 95: e4160. 